\title{
Modeling of Gas Solubility Using the Electrolyte Cubic Plus Association Equation of State
}

\section{Sun, Li; Kontogeorgis, Georgios M.; von Solms, Nicolas; Liang, Xiaodong}

Published in:

Industrial and Engineering Chemistry Research

Link to article, DOI:

10.1021/acs.iecr.9b03335

Publication date:

2019

Document Version

Peer reviewed version

Link back to DTU Orbit

Citation (APA):

Sun, L., Kontogeorgis, G. M., von Solms, N., \& Liang, X. (2019). Modeling of Gas Solubility Using the Electrolyte Cubic Plus Association Equation of State. Industrial and Engineering Chemistry Research, 58(37), 1755517567. https://doi.org/10.1021/acs.iecr.9b03335

\section{General rights}

Copyright and moral rights for the publications made accessible in the public portal are retained by the authors and/or other copyright owners and it is a condition of accessing publications that users recognise and abide by the legal requirements associated with these rights.

- Users may download and print one copy of any publication from the public portal for the purpose of private study or research.

- You may not further distribute the material or use it for any profit-making activity or commercial gain

- You may freely distribute the URL identifying the publication in the public portal 


\title{
Thermodynamics, Transport, and Fluid Mechanics
}

Subscriber access provided by DTU Library

\section{Modeling of Gas Solubility using the Electrolyte Cubic Plus Association Equation of State}

\author{
Li Sun, Georgios M. Kontogeorgis, Nicolas von Solms, and Xiaodong Liang
}

Ind. Eng. Chem. Res., Just Accepted Manuscript • DOI: 10.1021/acs.iecr.9b03335 • Publication Date (Web): 21 Aug 2019

Downloaded from pubs.acs.org on August 24, 2019

\section{Just Accepted}

"Just Accepted" manuscripts have been peer-reviewed and accepted for publication. They are posted online prior to technical editing, formatting for publication and author proofing. The American Chemical Society provides "Just Accepted" as a service to the research community to expedite the dissemination of scientific material as soon as possible after acceptance. "Just Accepted" manuscripts appear in full in PDF format accompanied by an HTML abstract. "Just Accepted" manuscripts have been fully peer reviewed, but should not be considered the official version of record. They are citable by the Digital Object Identifier (DOI®). "Just Accepted" is an optional service offered to authors. Therefore, the "Just Accepted" Web site may not include all articles that will be published in the journal. After a manuscript is technically edited and formatted, it will be removed from the "Just Accepted" Web site and published as an ASAP article. Note that technical editing may introduce minor changes to the manuscript text and/or graphics which could affect content, and all legal disclaimers and ethical guidelines that apply to the journal pertain. ACS cannot be held responsible for errors or consequences arising from the use of information contained in these "Just Accepted" manuscripts. 


\title{
Modeling of Gas Solubility using the Electrolyte Cubic Plus Association Equation of State
}

\author{
Li Sun, Georgios M. Kontogeorgis, Nicolas von Solms, Xiaodong Liang* \\ Center for Energy Resources Engineering \\ Department of Chemical and Biochemical Engineering \\ Technical University of Denmark \\ 2800-Kongens Lyngby, Denmark
}

Keywords: Gas Solubility; Inorganic Salts; Electrolyte Solution; e-CPA; Multi-salt solution 


\begin{abstract}
The prediction of the solubilities of carbon dioxide and methane in aqueous solutions of inorganic salts is important for geological carbon storage, enhanced oil recovery, gas hydrate formation and seawater desalination. Few electrolyte equations of state can be used for accurate gas solubility calculations over wide ranges of temperature, pressure and salt molality. This work presents a thermodynamic modeling study on the solubilities of carbon dioxide and methane in aqueous solutions of several inorganic salts with the electrolyte Cubic-Plus-Association equation of state. The binary interaction parameters between ion and gas are obtained by fitting the experimental data of gas solubility in single-salt solutions. It is shown that the equation of state can satisfactorily correlate the gas solubility over a wide range of conditions, with deviation less than the reported experimental uncertainties (7\%) for most systems. The equation of state is then used to predict the gas solubility in multi-salt solutions, and a satisfactory performance is achieved. The saltingout effects resulting from ion size, charge density, and salt concentration are also extensively discussed.
\end{abstract}




\section{Introduction}

One important way of reducing carbon dioxide $\left(\mathrm{CO}_{2}\right)$ emissions is to capture and inject it into deep saline formations. The injected $\mathrm{CO}_{2}$ dissolves into the saline pore water and forms an aqueous solution. That is why some inorganic salts, such as sodium chloride $(\mathrm{NaCl})$, potassium chloride $(\mathrm{KCl})$, calcium chloride $\left(\mathrm{CaCl}_{2}\right)$, magnesium chloride $\left(\mathrm{MgCl}_{2}\right)$, and sodium sulfate $\left(\mathrm{Na}_{2} \mathrm{SO}_{4}\right)$, water $\left(\mathrm{H}_{2} \mathrm{O}\right)$, and $\mathrm{CO}_{2}$ are the most common species in geological fluids ${ }^{1}$. Methane $\left(\mathrm{CH}_{4}\right)$, another important greenhouse gas, has also been found in many geological fluids ${ }^{2}$. Some inorganic salts (such as $\mathrm{NaCl}$ and $\mathrm{KCl}$ ) are common thermodynamic inhibitors for gas hydrate formation, because these salts can significantly shift the phase equilibria of hydrate and aqueous solution ${ }^{3}$. Accurate calculations of gas solubility over a wide range of conditions (temperature, pressure and salt concentration) is are important for the analysis of fluid inclusion data $^{4}$, geological carbon storage ${ }^{5}$, the prediction of gas hydrate formation, as well as in the applications, such as enhanced oil recovery, seawater desalination and designing certain separation equipment in the chemical industries ${ }^{6}$.

Thermodynamic modeling is an attractive approach for calculating gas solubility. Extensive thermodynamic modeling studies have been made for calculating the solubilities of $\mathrm{CO}_{2}$ and $\mathrm{CH}_{4}$ in aqueous solutions of inorganic salts. The so-called $\varphi-\gamma$ approach has played a vital role in these studies ${ }^{6-24}$. The equations of state (EOS) of Peng-Robinson $(\mathrm{PR})^{25}$, Soave-Redlich-Kwong (SRK) ${ }^{26}$, Redlich-Kwong $(\mathrm{RK})^{27}$, Virial truncated after the second term ${ }^{16,18}$, Patel and Teja $(\mathrm{PT})^{28}$ and Perturbed-Chain statistical associating fluid 
theory (PC-SAFT) $)^{29,30}$ have been used for modeling the fugacity coefficient $(\varphi)$, while LIFAC $^{31}$, extended UNIQUAC ${ }^{32}$, Non-Random Two-Liquid (NRTL) ${ }^{33}$, Pitzer's equation ${ }^{34}$, electrolyte NRTL $^{35,36}$ and empirical correlations ${ }^{7}$ are typical choices for the activity coefficient $(\gamma)$. This $\varphi-\gamma$ approach usually requires many adjustable parameters (even up to 20 for a single-salt solution ${ }^{23}$ ), and it has not been used for modeling gas solubility in multi-salt solutions.

An electrolyte EOS for all the phases provides a more consistent framework, as well as the possibility to calculate other properties, e.g. density and surface tension. Some practices have also been done for modeling the solubilities of $\mathrm{CO}_{2}$ and $\mathrm{CH}_{4}$ in aqueous salt solutions $^{37-49}$. Unfortunately, on one hand, a few electrolyte EOS can predict gas solubility over wide ranges of temperature, pressure and salt concentration with accuracy close to the experimental one, and fewer studies made systematic investigations. On the other hand, if the electrolyte EOS is set up for ions, it shall in principle be working for multi-salt solutions. To the best of our knowledge, however, no research on modeling gas solubility in aqueous multi-salt solutions has been reported for electrolyte EOS. More discussion is presented in Section 4 .

The electrolyte cubic plus association (CPA) EOS developed by Maribo-Mogensen et al. ${ }^{49}$ is investigated in this work for modeling the gas solubilities of $\mathrm{CO}_{2}$ and $\mathrm{CH}_{4}$ in single-salt and multi-salt solutions. In the rest of the paper, the model is firstly presented, and then the data and parameter estimation are discussed. And then the results are presented and discussed followed by a summary discussion. Finally, the conclusion is given. 


\section{Thermodynamic Model}

\subsection{The Electrolyte CPA EOS}

The electrolyte CPA EOS (e-CPA) ${ }^{49}$ is an extension of the CPA EOS ${ }^{50}$

$$
A^{r}=A^{S R K}+A^{A S S O C}+A^{D H}+A^{B o r n}
$$

where $A^{S R K}$ and $A^{A S S O C}$ are the two contributions from the original CPA, $A^{D H}$ is from the Debye-Hückel (DH) theory ${ }^{51}$, and $A^{\text {Born }}$ is from the Born equation ${ }^{52}$.

In terms of residual Helmholtz energy, the cubic Soave-Redlich-Kwong EOS $^{26}$ can be written

$$
A^{S R K}=n R T\left[-\ln \left(1-\frac{\mathrm{b}}{\mathrm{v}}\right)-\frac{a(T)}{b R T} \ln \left(1+\frac{b}{v}\right)\right]
$$

where $R$ is the gas constant, $T$ is the temperature, $v$ is the molar volume, $n$ is the total number of moles, and $b$ is the co-volume parameter of the mixture

$$
b=\sum_{i} x_{i} b_{i}
$$

where $x_{i}$ and $b_{i}$ are respectively the mole fraction and the pure co-volume parameter of component $i$ (solvent, gas, cation, anion).

For the binary of water and gas, the classical one-fluid mixing rule is used for the temperature dependent energy parameter of the mixture $a(T)$

$$
a(T)=\sum_{i} \sum_{j} x_{i} x_{j} \sqrt{a_{i}(T) a_{j}(T)}\left(1-k_{i j}\right)
$$

with

$$
a_{i}(T)=a_{0 i}\left(1+c_{1 i}\left(1-\sqrt{T_{r i}}\right)\right)^{2}
$$

where $T_{r i}$ is the reduced temperature of component $i$, defined as $T_{r i}=T / T_{c i}$, and $T_{c i}$ is the critical temperature of component $i$. 
For the binary involving an ion, the Huron-Vidal/NRTL (HV-NRTL) mixing rule is used, due to its additional flexibility for electrolyte systems ${ }^{49,53}$

$$
\begin{aligned}
& \frac{a}{b}=\sum_{i} x_{i} \frac{a_{i}}{b_{i}}-\frac{g^{E, \infty}}{\ln 2} \\
& \frac{g^{E, \infty}}{R T}=\sum_{i} x_{i} \frac{\sum_{j} x_{j} b_{j} \exp \left(-\alpha_{j i} \frac{\Delta U_{j i}}{R T}\right) \frac{\Delta U_{j i}}{R T}}{\sum_{j} x_{j} b_{j} \exp \left(-\alpha_{j i} \frac{\Delta U_{j i}}{R T}\right)}
\end{aligned}
$$

where $g^{E, \infty}$ is the excess Gibbs energy at infinite pressure, $\alpha_{j i}$ is the non-randomness parameter, and $\Delta U_{j i}$ is the change in interaction energy between the unlike and the like interactions $\left(\Delta U_{j i}=\Delta U_{i j}-\Delta U_{j j}\right)$, for which a quadratic temperature dependence is used

$$
\frac{\Delta U_{i j}}{R}=\frac{\Delta U_{i j}^{r e f}}{R}+\omega_{\Delta U_{i j}}\left[\left(1-\frac{T}{T_{\Delta U_{i j}}}\right)^{2}-\left(1-\frac{T_{r e f}}{T_{\Delta U_{i j}}}\right)^{2}\right]
$$

where $\Delta U_{i j}^{r e f}$ is a binary interaction parameter between ion and solvent or gas at the reference temperature, $\omega_{\Delta U_{i j}}$ is an adjustable parameter for the linear dependency, and $T_{\Delta U_{i j}}$ is a parameter of the temperature dependency. $T_{r e f}$ is the reference temperature at which $\Delta U_{i j}^{r e f}$ is valid, and it is set to $298.15 \mathrm{~K}$ in this work.

It is worth pointing out that the HV-NRTL mixing rule has the flexibility to reduce to the classical one-fluid mixing rule, i.e. equation (4) can be integrated into equations (6) and (7). More details can be found in the book ${ }^{54}$.

The residual Helmholtz energy for association $A^{A S S O C}$ is obtained from $55,56,57,58$

$$
A^{a s s o c}=R T\left[\sum_{i} n_{i} \sum_{A_{i}}\left(\ln X_{A_{i}}-\frac{1}{2} X_{A_{i}}+\frac{1}{2}\right)\right]
$$




$$
\frac{1}{X_{A_{i}}}=1+\sum_{j} \rho_{j} \sum_{B_{i}} X_{B_{j}} \Delta_{A_{i} B_{j}}
$$

where $n_{i}$ is the number of moles of component $i, X_{A_{i}}$ is the fraction of site $\mathrm{A}$ on component $i$ that is not bonded to any other site, $\rho_{j}$ is the density of component $j$, and $\Delta_{A_{i} B_{j}}$ is the association strength

$$
\Delta_{A_{i} B_{j}}=g(\rho)\left[\exp \left(\frac{\varepsilon^{A_{i} B}{ }_{j}}{k_{B} T}\right)-1\right] b_{i j} \beta^{A_{i} B_{j}}
$$

where $\varepsilon^{A_{i} B_{j}}$ and $\beta^{A_{i} B_{j}}$ are the association energy and the association volume, respectively. $b_{i j}$ follows the combing rule $b_{i j}=\left(b_{i}+b_{j}\right) / 2$, and $g(\rho)$ is the simplified radial distribution function given by $g(\rho)=(1-1.9 \eta)^{-1}$, where $\eta$ is the packing fraction equal to $b / 4 v$.

The residual Helmholtz energy from the long-range ionic interactions is calculated from the DH theory ${ }^{51}$, as shown in the following equation,

$$
A^{D H}=-\frac{k_{B} T V}{4 \pi N_{A} \sum_{i} n_{i} Z_{i}^{2}} \sum_{i} n_{i} Z_{i}^{2} \chi_{i}
$$

where $k_{B}$ and $N_{A}$ are respectively the Boltzmann constant and the Avogadro constant, $V$ is the total volume, $Z_{i}$ is the charge of component $i$, and $\chi_{i}$ is merely an auxiliary function

$$
\chi_{i}=\frac{1}{d_{i}^{3}}\left[\ln \left(1+\kappa d_{i}\right)-\kappa d_{i}+\frac{1}{2}\left(\kappa d_{i}\right)^{2}\right]
$$

where $\kappa$ is the inverse Debye screening length, and $d_{i}$ is the distance of closest approach of ion $i$.

The residual Helmholtz energy from the ion solvation is described by the Born equation ${ }^{52,59}$ 


$$
A^{\text {Born }}=\frac{N_{A} e^{2}}{8 \pi \varepsilon_{0}} \sum_{i} \frac{n_{i} Z_{i}^{2}}{r_{B o r n, i}}\left(\frac{1}{\varepsilon_{r}}-1\right)
$$

where $e$ is the elementary charge and $r_{B o r n, i}$ is the Born radius.

The relative static permittivity (also called dielectric constant) $\varepsilon_{\mathrm{r}}$ plays a central role in the thermodynamics of electrolyte solutions ${ }^{60}$. In e-CPA, the theory proposed by MariboMogensen et al. ${ }^{61}$ for predicting the relative static permittivity is used. For more details, the reader is referred to the work of Maribo-Mogensen et al. ${ }^{49}$.

\section{Data and Parameter Estimation}

\subsection{Data Analysis}

Sometimes experimental data may represent large uncertainties because of the experimental apparatus, measurement methods and/or operations. In order to obtain accurate binary interaction parameters between ion and gas, and ensure that the model describes the actual phase behavior, experimental data have been analyzed and filtered prior to modeling.

Duan and $\operatorname{Sun}^{17}$ collected and analysed the solubility data of $\mathrm{CO}_{2}$ in aqueous $\mathrm{NaCl}$ solution, and concluded that most experimental data sets were consistent within errors of about $7 \%$. Yan et al. ${ }^{62}$ made an extensive review for the solubility data of $\mathrm{CO}_{2}$ in aqueous $\mathrm{NaCl}$ solution, and concluded that the solubility data measured by Kiepe et al. ${ }^{10}$ and Drummond ${ }^{63}$ were doubtful. Yan et al. ${ }^{62}$ pointed out further that most solubility data of $\mathrm{CO}_{2}$ in aqueous $\mathrm{NaCl}$ solution at high pressure were from three data sources: Takenouchi and Kennedy ${ }^{64}$, Rumpf et al. ${ }^{16}$, and Koschel et al. ${ }^{65}$. 
Duan et al. ${ }^{2}$ reviewed the experimental data of the solubility of $\mathrm{CH}_{4}$ in aqueous $\mathrm{CaCl}_{2}$ solution from Blanco and Smith ${ }^{66}$, and determined the valid range, i.e. from 25 to $125^{\circ} \mathrm{C}$ and from 100 to 600 bar. Duan et al. ${ }^{2}$ pointed out that the most comprehensive data reported for the solubility of $\mathrm{CH}_{4}$ in aqueous $\mathrm{NaCl}$ solution were from Blount et al. ${ }^{67}$, while Price et al ${ }^{68}$ pointed out an experimental error in Blount et al.'s work ${ }^{67}$, and they concluded that about $70 \%$ of the solubility data points for pressure below 300 bar had a high deviation (10-35\%). Duan et al. ${ }^{2}$ pointed out that the data from Duffy et al. ${ }^{69}$ and Michels et al. ${ }^{70}$ showed large uncertainties. Moreover, Duan et al. ${ }^{2}$ suggested not using the solubility data of $\mathrm{CH}_{4}$ in aqueous $\mathrm{NaCl}$ solution from Barta and Bradley ${ }^{71}$ and Drummond ${ }^{63}$. In a later work, Duan et al. ${ }^{72}$ pointed out that experimental data for the solubility of $\mathrm{CH}_{4}$ in aqueous $\mathrm{CaCl}_{2}$ solution from Duffy et al. ${ }^{69}$ and Michels et al. ${ }^{70}$ were unreliable, as were those in $\mathrm{NaCl}$ solutions, due to adopting an inaccurate pressure decline technique. Pérez-Salado et al. ${ }^{21}$ stated that the data from Kiepe et al. ${ }^{10}$ had low credibility.

It is known from Takenouchi and Kennedy ${ }^{73}$ and Tödheide and Franck ${ }^{74}$ that the change of the solubility of $\mathrm{CO}_{2}$ with pressure at temperatures above $538 \mathrm{~K}$ differs sharply from that at temperatures below $538 \mathrm{~K}$. In this work, therefore, the modelling temperature is set to lower than $538 \mathrm{~K}$. Moreover, the range of salt molality of most collected data follows the work of Maribo-Mogensen et al. ${ }^{49}$ i.e. $\mathrm{NaCl}: 6 \mathrm{~mol} / \mathrm{kg}$ water, $\mathrm{KCl}$ : $6 \mathrm{~mol} / \mathrm{kg}$ water, $\mathrm{CaCl}_{2}$ : $3 \mathrm{~mol} / \mathrm{kg}$ water, $\mathrm{MgCl}_{2}: 2 \mathrm{~mol} / \mathrm{kg}$ water, and $\mathrm{Na}_{2} \mathrm{SO}_{4}: 2 \mathrm{~mol} / \mathrm{kg}$ water.

The solubility data of $\mathrm{CO}_{2}$ in aqueous solutions of salts other than $\mathrm{NaCl}$ and $\mathrm{CaCl}_{2}$, and the solubility data of $\mathrm{CH}_{4}$ in aqueous solutions of salts other than $\mathrm{NaCl}, \mathrm{KCl}$ and $\mathrm{CaCl}_{2}$ are 
limited. Moreover, the overlapping space is very small, and a clear conclusion cannot be reached regarding the reliability of these data sets. For the gas solubility in aqueous multisalt solutions, the experimental data are limited and scattered. Therefore, all these collected data of aqueous multi-salt solutions are considered reliable.

\subsection{Parameter Estimation}

As presented above, e-CPA is set up for ions, i.e. the model parameters are by nature ion specific. The pure component e-CPA parameters of an ion are: $b_{i}, \Gamma_{i}\left(=a_{0 i} / R b_{i}\right), c_{1 i}$, $\varepsilon^{A_{i} B_{i}}, \beta^{A_{i} B_{i}}, d_{i}$ and $r_{B o r n, i}$. The binary interaction parameters of ion and another species are: $\alpha_{i j}, \Delta U_{i j}^{r e f}, \omega_{\Delta U_{i j}}$ and $T_{\Delta U_{i j}}$. In order to minimize the number of parameters, the following assumptions have been made ${ }^{49}$ : the CPA reduced energy parameter $\left(\Gamma_{i}\right)$ and the temperature dependence parameter $\left(c_{1 i}\right.$ in Eq. (5)) of ions are both set to zero; the ions are assumed to be non-associating, thus eliminating the two association parameters; the three size parameters $b_{i}, d_{i}$ and $r_{B o r n, i}$ are connected with only one adjustable parameter left ${ }^{75}$. the NRTL non-randomness factor and the ion-ion interaction parameters are set to zero. In this work, ion-solvent and ion-gas interaction parameters are transformed to cation/anionsolvent, and cation/anion-gas interaction parameters, which means that the interaction parameter $\Delta U_{\text {cation-solvent }}$ is equal to $\Delta U_{\text {anion-solvent, }}$, and $U_{\text {cation-gas }}$ is equal to $\Delta$ $U_{\text {anion-gas }}$

The objective function used for the regression is

$$
F=\sum\left[\frac{x_{i}^{c a l}-x_{i}^{e x p}}{x_{i}^{e x p}}\right]^{2}
$$


where $x_{i}^{c a l}$ represents the calculated solubility (mole fraction), and $x_{i}^{\text {exp }}$ represents the experimental solubility (mole fraction of gas in liquid phase).

The results are typically listed as absolute average deviation (AAD) defined by

$$
A A D \%=\frac{1}{N p} \sum_{i}^{N p}\left|\frac{y_{i}^{c a l}-y_{i}^{e x p}}{y_{i}^{e x p}}\right| \times 100 \%
$$

where $N p$ is the number of data points, $y_{i}^{c a l}$ and $y_{i}^{\text {exp }}$ respectively represent the calculated results and experimental value of any property, e.g. solubility, osmotic coefficient, or water activity.

The gas solubility in aqueous solutions is calculated by a two-phase PT-flash with the successive substitution method ${ }^{54,76}$. The physical properties and pure component e-CPA parameters are taken from literature and summarized in Tables S1-S2 of Supporting Information.

\section{Results and Discussion}

\subsection{Binary Systems}

Before modelling the $\mathrm{H}_{2} \mathrm{O}$-salt-gas ternary systems, the performance of e-CPA on $\mathrm{H}_{2} \mathrm{O}$ gas, and $\mathrm{H}_{2} \mathrm{O}$-salt binary systems has been evaluated. Gas solubility is the maximum quantity of gaseous solutes that can dissolve in a certain quantity of solvent at a specified temperature and pressure ${ }^{77}$. $\mathrm{CO}_{2}$ and $\mathrm{CH}_{4}$ are not very soluble in $\mathrm{H}_{2} \mathrm{O}$. The dissolution of $\mathrm{CO}_{2}$ in $\mathrm{H}_{2} \mathrm{O}$ contains an additional equilibrium of two acids, which can increase the solubility of $\mathrm{CO}_{2}$ in $\mathrm{H}_{2} \mathrm{O}^{78}$. The evaluation results are presented in Table 1 together with temperature-dependent binary interaction parameters, and $\mathrm{CO}_{2}$ is considered as a nonassociating fluid in this work. On one hand, e-CPA can satisfactorily correlate the solubility 
of $\mathrm{CO}_{2}$ in water with the binary interaction parameter from literature, and large deviations are only found at low pressure and high temperature. On the other hand, with the published interaction parameters ${ }^{79}$, e-CPA cannot describe the solubility of $\mathrm{CH}_{4}$ in $\mathrm{H}_{2} \mathrm{O}$ accurately for the experimental data collected in this work. This might be because the temperature range and data used in correlation are different, and it leads to a new correlation as given in Table 1. It needs to be pointed out that the existence of two liquid phases has not been taken into account in this work, and the same strategy is applied for the modelling of ternary systems below.

Table 1. Modelling performance of gas solubility in pure $\mathrm{H}_{2} \mathrm{O}$ with e-CPA *

\begin{tabular}{|c|c|c|c|c|c|c|}
\hline \multirow{2}{*}{ Gas } & \multirow{2}{*}{$k_{i j}$} & \multirow{2}{*}{$\mathrm{T}[\mathrm{K}]$} & \multicolumn{4}{|c|}{ Evaluation results } \\
\hline & & & $\mathrm{T}[\mathrm{K}]$ & $\mathrm{P}[\mathrm{MPa}]$ & $\mathrm{Np}$ & $\mathrm{AAD}[\%]$ \\
\hline \multirow{3}{*}{$\mathrm{CO}_{2}$} & \multirow{3}{*}{$-0.15508+0.000877 \mathrm{~T}^{80}$} & $298.15-$ & $273.75-$ & $0.095-$ & \multirow{3}{*}{328} & \multirow{3}{*}{8.3} \\
\hline & & & & & & \\
\hline & & 477.6 & 473.15 & 82.88 & & \\
\hline \multirow{3}{*}{$\mathrm{CH}_{4}$} & \multirow{3}{*}{$0.6769-213.5 / \mathrm{T}^{79}$} & $274.0-$ & 274.19- & $0.101-$ & \multirow{3}{*}{206} & \multirow{3}{*}{12.2} \\
\hline & & & & & & \\
\hline & & 473.0 & 444.26 & 100.0 & & \\
\hline \multirow{3}{*}{$\mathrm{CH}_{4}$} & \multirow{3}{*}{$0.8243-245.33 / \mathrm{T}$} & 274.19- & 274.19- & $0.101-$ & \multirow{3}{*}{206} & \multirow{3}{*}{4.5} \\
\hline & & & & & & \\
\hline & & 444.26 & 444.26 & 100.0 & & \\
\hline
\end{tabular}

${ }^{*}$ The first $\mathrm{T}[\mathrm{K}]$ is the temperature range used in the binary interaction parameter regression.

$N p$ is the number of data points. The data of $\mathrm{H}_{2} \mathrm{O}-\mathrm{CO}_{2}$ and $\mathrm{H}_{2} \mathrm{O}-\mathrm{CH}_{4}$ are taken from 
literature $7,10,62,73,81-87$ and literature ${ }^{88-94}$, respectively.

The binary systems of $\mathrm{H}_{2} \mathrm{O}-\mathrm{NaCl}, \mathrm{H}_{2} \mathrm{O}-\mathrm{KCl}, \mathrm{H}_{2} \mathrm{O}-\mathrm{CaCl}_{2}, \mathrm{H}_{2} \mathrm{O}-\mathrm{MgCl}_{2}$, and $\mathrm{H}_{2} \mathrm{O}-\mathrm{Na}_{2} \mathrm{SO}_{4}$ have been investigated previously. The modelling performance of e-CPA on mean ionic activity coefficients and osmotic coefficients of these systems are shown in Figure 1, and more details can be found in Table S3 of Supporting Information. It is readily seen that eCPA with the binary interaction parameters from literature ${ }^{49}$ can correlate the mean ionic activity coefficients and osmotic coefficients of $\mathrm{H}_{2} \mathrm{O}$-salt binary systems very well.

It is worth mentioning that the mean ionic activity coefficients and osmotic coefficients of aqueous solutions of $\mathrm{NaCl}, \mathrm{KCl}, \mathrm{CaCl}_{2}, \mathrm{MgCl}_{2}$ and $\mathrm{Na}_{2} \mathrm{SO}_{4}$ exhibit different trends. The activity coefficients for aqueous solutions of $\mathrm{CaCl}_{2}$ and $\mathrm{MgCl}_{2}$ decrease first and then increase sharply as the salt concentration increases. These properties of the aqueous $\mathrm{Na}_{2} \mathrm{SO}_{4}$ solutions are smaller than those of other systems. 


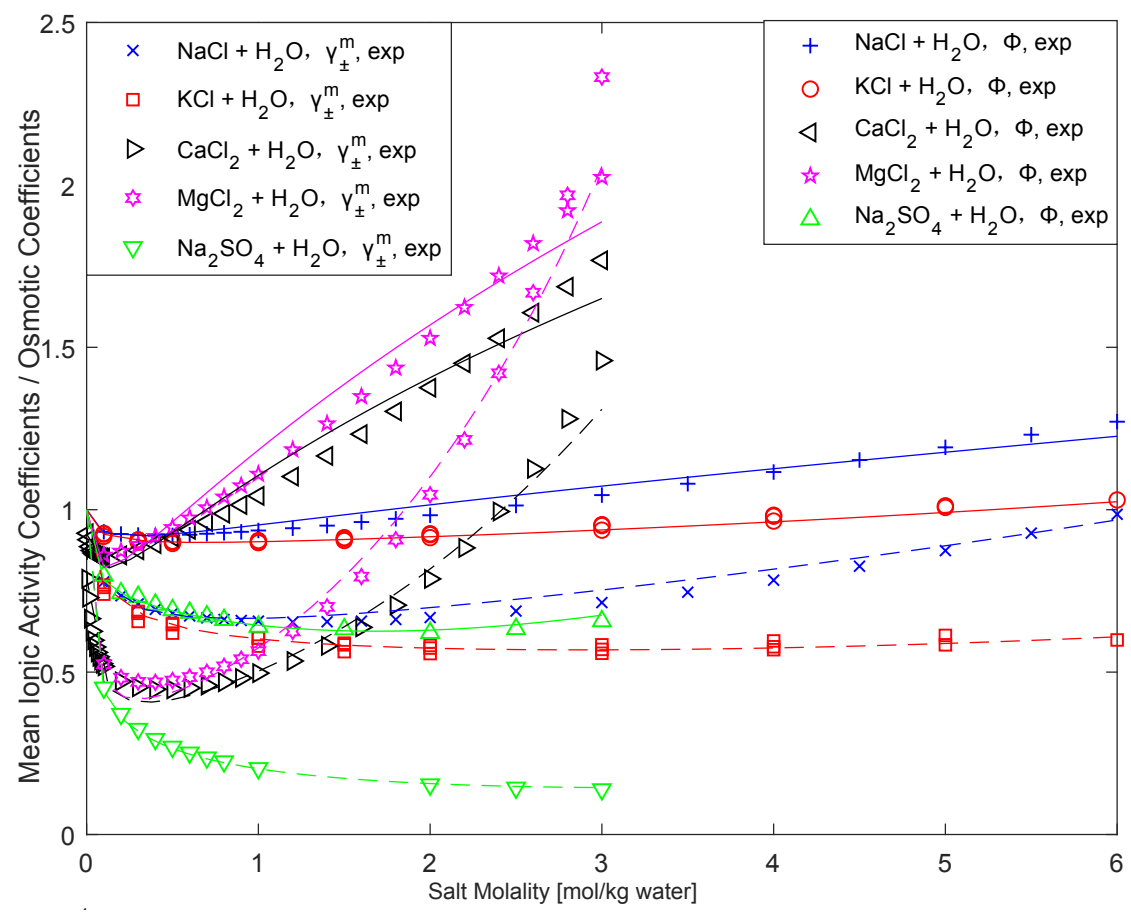

Figure 1. Experimental and calculated mean ionic activity coefficients and osmotic coefficients for binary systems at $298.15 \mathrm{~K}: \mathrm{H}_{2} \mathrm{O}-\mathrm{NaCl}^{195,96} ; \mathrm{H}_{2} \mathrm{O}-\mathrm{KCl}^{97} ; \mathrm{H}_{2} \mathrm{O}-\mathrm{CaCl}_{2}{ }^{98}$; $\mathrm{H}_{2} \mathrm{O}-\mathrm{MgCl}_{2}{ }^{99}, \mathrm{H}_{2} \mathrm{O}-\mathrm{Na}_{2} \mathrm{SO}_{4}{ }^{100}$. Dash lines are for mean ionic activity coefficients and solid lines are for osmotic coefficients. $\gamma_{ \pm}^{m}$ and $\Phi$ represent mean ionic activity coefficients and osmotic coefficients, respectively.

\section{2 $\mathrm{H}_{2} \mathrm{O}$-salt-gas Ternary Systems}

The temperature dependency $T_{\Delta U_{i j}}$ was respectively set to $340 \mathrm{~K}$ and $300 \mathrm{~K}$ for chloride salts and sulfate salts in the work of Maribo-Mogensen et al. ${ }^{49}$. In this work, three fitting approaches have been investigated for the regression of the ion-gas binary interaction parameters, as listed in Table 2. Approach A has 3 adjustable parameters (including 2 temperature-dependent parameters), Approach B has 2 adjustable parameters (including 1 
temperature-dependent parameter), and Approach $\mathrm{C}$ has 1 adjustable parameter (no temperature-dependent parameters).

Table 2. Fitting approaches of ion-gas interaction parameters used in this work.

\begin{tabular}{cccc}
\hline Approaches & $\Delta U_{i j}^{r e f} / R[\mathrm{~K}]$ & $T_{\Delta U_{i j}}[\mathrm{~K}]$ & $\omega_{\Delta U_{i j}}[\mathrm{~K}]$ \\
\hline A & adjustable & adjustable & adjustable \\
B & adjustable & $340 \mathrm{~K}$ (for chloride salts) & \\
& & $300 \mathrm{~K}$ (for sulfate salts) & adjustable \\
C & adjustable & - & - \\
\hline
\end{tabular}

Table 3 summarizes the ion-gas binary interaction parameters and the performance of eCPA on correlating the gas solubility with Approach A. It can be seen, on one hand, that the energy interaction parameters $\Delta U_{i j}^{r e f} / R$ of ion- $\mathrm{CO}_{2}$ and ion- $\mathrm{CH}_{4}$ follow the same order: $\mathrm{NaCl}>\mathrm{KCl}>\mathrm{CaCl}_{2}>\mathrm{MgCl}_{2}$, and $\Delta U_{i j}^{r e f} / R$ of $\mathrm{Na}_{2} \mathrm{SO}_{4}-\mathrm{CO}_{2}$ has the highest value: $1449.66 \mathrm{~K}$. On the other hand, the deviations (AAD\%) are very satisfactory, less than the aforementioned experimental uncertainty $7 \%$ for most of the investigated systems. For the results of $\mathrm{H}_{2} \mathrm{O}-\mathrm{NaCl}-\mathrm{CH}_{4}$ system, the larger deviations of the solubility of $\mathrm{CH}_{4}{ }^{67}$ might be from high temperatures (up to $513.15 \mathrm{~K}$ ), as the binary interaction parameters between $\mathrm{CH}_{4}$ and $\mathrm{H}_{2} \mathrm{O}$ are obtained by fitting the data up to $444.26 \mathrm{~K}$, in a combination of the doubtful data $^{67}$ as discussed above. 
Table S4 of Supporting Information lists the details of the modelling results for all three approaches. Approach A shows an overall better performance than Approaches B and C, which is to be expected as there are more adjustable parameters. It needs to be pointed out that Approach A, from a mathematical point of view, is in general more sensitive to the data used in the parameter fitting than the two other approaches. Approach A and Approach B can be recommended when there are enough data over a wide range of temperature available, while Approach $\mathrm{C}$ is recommended if limited data are available and extrapolations are required. With Approach C, the binary interaction parameters of $\mathrm{Na}^{+} / \mathrm{Cl}^{-}-$ $\mathrm{CO}_{2}$ and that of $\mathrm{Na}^{+} / \mathrm{Cl}^{-}-\mathrm{CH}_{4}$ are not the same but close to what were reported by MariboMogensen et al. ${ }^{49}\left(\Delta U_{i j}^{r e f} / R=816.4 \mathrm{~K}\right.$ versus $724.8 \mathrm{~K}$ for $\mathrm{Na}^{+} / \mathrm{Cl}^{-}-\mathrm{CO}_{2}$, and $\Delta U_{i j}^{r e f} / R=$ $1329 \mathrm{~K}$ versus $1128 \mathrm{~K}$ for $\left.\mathrm{Na}^{+} / \mathrm{Cl}^{-}-\mathrm{CH}_{4}\right)$. The small differences are due to the different binary interaction parameters between $\mathrm{H}_{2} \mathrm{O}$ and gas, as well as the different experimental data. It is a good indication that Approach $\mathrm{C}$ is not so sensitive to the data, and with this approach Maribo-Mogensen et al. ${ }^{49}$ showed the predictive capability of e-CPA for the solubility of $\mathrm{CO}_{2}$ and $\mathrm{CH}_{4}$ in $\mathrm{NaCl}$ containing systems. In the following part of this work, Approach $\mathrm{A}$ is used except for the $\mathrm{H}_{2} \mathrm{O}-\mathrm{MgCl}_{2}-\mathrm{CH}_{4}$ system which is modeled with Approach $\mathrm{C}$ because of the limited number of data points. 
Table 3. Ion-gas interaction parameters and model performance of e-CPA on correlating the gas solubility.

\begin{tabular}{|c|c|c|c|c|c|c|c|c|}
\hline \multirow{2}{*}{ Gas } & \multirow{2}{*}{$\mathrm{T}[\mathrm{K}]$} & \multirow{2}{*}{$\mathrm{P}[\mathrm{MPa}]$} & \multirow{2}{*}{$\mathrm{m}[\mathrm{mol} / \mathrm{kg}$ water $]$} & \multirow{2}{*}{$\mathrm{Np}^{\text {a }}$} & \multicolumn{4}{|c|}{ Interaction Parameters } \\
\hline & & & & & $\Delta U_{i j}^{r e f} / R[\mathrm{~K}]$ & $T_{\Delta U_{i j}}[\mathrm{~K}]$ & $\omega_{\Delta U_{i j}}[\mathrm{~K}]$ & $\operatorname{AAD}^{\mathrm{b}}[\%]$ \\
\hline \multicolumn{9}{|c|}{$\mathrm{H}_{2} \mathrm{O}-\mathrm{NaCl}$-gas } \\
\hline $\mathrm{CO}_{2}$ & $273.15-523.15$ & $0.101-141.855$ & $0.1-6.0$ & $435^{16,62,64,65,101-105}$ & 644.84 & 251.07 & 596.44 & 6.6 \\
\hline $\mathrm{CH}_{4}$ & $298.15-513.15$ & $2.413-89.632$ & $0.349-5.71$ & $137^{67,106,107}$ & 1107.70 & 282.46 & 2963.99 & 12.0 \\
\hline $\mathrm{CH}_{4}{ }^{\mathrm{c}}$ & 298.15-398.15 & $2.413-61.606$ & $0.5-4.0$ & $57^{106,107}$ & 1110.46 & 276.18 & 2499.19 & 3.4 \\
\hline $\mathrm{CH}_{4}{ }^{\mathrm{c}}$ & $373.15-513.15$ & $48.26-89.632$ & $0.349-5.71$ & $80^{67}$ & 849.42 & 305.29 & 1018.36 & 7.9 \\
\hline \multicolumn{9}{|c|}{$\mathrm{H}_{2} \mathrm{O}-\mathrm{KCl}$-gas } \\
\hline $\mathrm{CO}_{2}$ & $273.35-433.1$ & $0.101-15.81$ & $0.1-4.5$ & $140^{21,101,103,108}$ & 510.80 & 449.22 & -3787.54 & 3.9 \\
\hline $\mathrm{CH}_{4}$ & $298.15-373.21$ & $0.419-9.791$ & $0.5-4.0$ & $98^{107,109}$ & 1060.34 & 338.89 & 24562.08 & 8.4 \\
\hline \multicolumn{9}{|c|}{$\mathrm{H}_{2} \mathrm{O}-\mathrm{CaCl}_{2}$-gas } \\
\hline $\mathrm{CO}_{2}$ & $309.28-424.43$ & $1.53-71.21$ & $0.117-3.0$ & $154^{101,108,110-112}$ & 199.49 & 703.17 & -912.99 & 5.7 \\
\hline $\mathrm{CH}_{4}$ & $298.15-398.15$ & $2.413-60.795$ & $0.50-2.0$ & $39^{66,107}$ & 612.76 & 714.10 & 15.00 & 4.9 \\
\hline \multicolumn{9}{|c|}{17} \\
\hline \multicolumn{9}{|c|}{ ACS Paragon Plus Environment } \\
\hline
\end{tabular}




\begin{tabular}{|c|c|c|c|c|c|c|c|c|}
\hline \multicolumn{9}{|c|}{$\mathrm{H}_{2} \mathrm{O}-\mathrm{MgCl}_{2}$-gas } \\
\hline $\mathrm{CO}_{2}$ & $309.58-424.63$ & $1.25-34.93$ & $0.333-2.0$ & $31^{108,110}$ & 96.71 & 378.86 & 4588.76 & 5.7 \\
\hline $\mathrm{CH}_{4}{ }^{\mathrm{d}}$ & 298.15 & $2.413-5.171$ & $0.5-2.16$ & $9^{107}$ & 239.13 & - & - & 4.5 \\
\hline \multicolumn{9}{|c|}{$\mathrm{H}_{2} \mathrm{O}-\mathrm{Na}_{2} \mathrm{SO}_{4}$-gas } \\
\hline $\mathrm{CO}_{2}$ & $313.11-433.16$ & $0.422-15.0$ & $0.333-2.01$ & $120^{18,108}$ & 1449.66 & 82.56 & 17.63 & 4.8 \\
\hline
\end{tabular}

a. $N p$ is the number of data points; b. AAD of gas solubility (molality of gas, [mol/kg water]); c. separate regression with different data sets as indicated by the references; d. Approach C. 


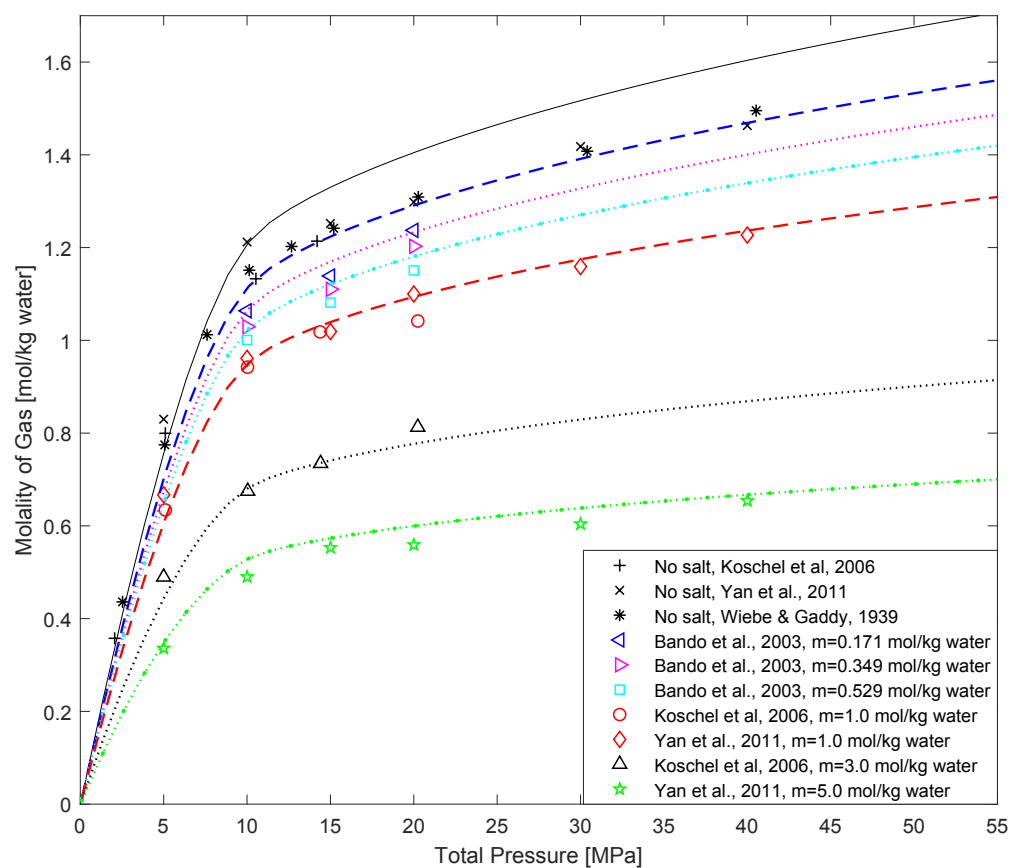

(a)

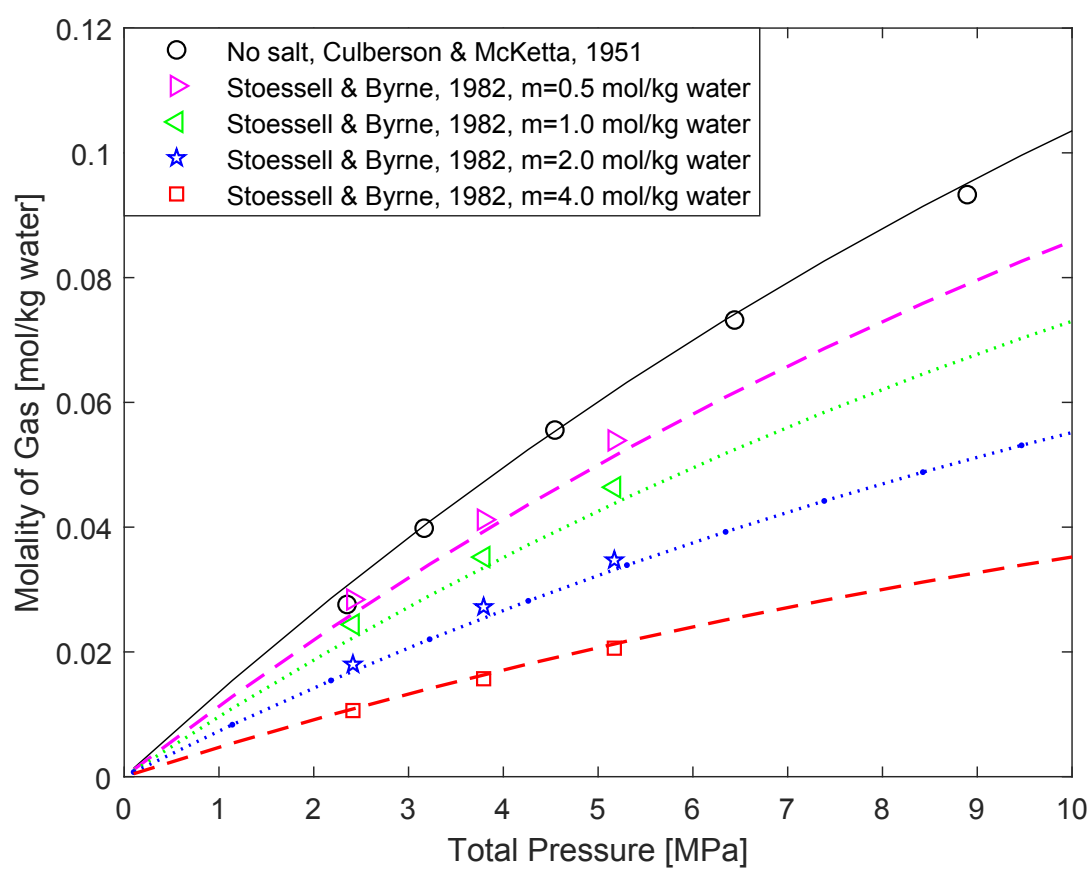

(b)

Figure 2. Comparison of the model results against the experimental data of the solubility of (a) $\mathrm{CO}_{2}$ in aqueous $\mathrm{NaCl}$ solution at $323.15 \mathrm{~K}^{62,65,102}$; (b) $\mathrm{CH}_{4}$ in aqueous $\mathrm{NaCl}$ solution at $298.15 \mathrm{~K}^{107}$. 
Figure 2 presents the solubilities of $\mathrm{CO}_{2}$ and $\mathrm{CH}_{4}$ in aqueous $\mathrm{NaCl}$ solution as a function of pressure at different salinity and a constant temperature. Figure 2 (a) shows that the solubility of $\mathrm{CO}_{2}$ decreases as the $\mathrm{NaCl}$ concentration increases, which is a typical 'saltingout' effect, defined as the reduction of the solubility of a gas due to the presence of ionic species in a solvent ${ }^{113}$. Carvalho et al. ${ }^{114}$ and Wiebe et al. ${ }^{82}$ found that the increase of the brine's salinity leaded to a reduction of $\mathrm{CO}_{2}$ dissolution, regardless of the system pressure and temperature. They explained the reduction of the solubility of $\mathrm{CO}_{2}$ in a brine solution on 'solvation' terms: involvement of $\mathrm{H}_{2} \mathrm{O}$ molecules in ions solvation made the dissolved $\mathrm{CO}_{2}$ out of the interstice of water molecules. They also pointed out that the salting-out effect was not that pronounced at low salinities, and the pressure dependency of the solubility reduced as the pressure increases ${ }^{82,114}$.

Similar with $\mathrm{CO}_{2}$, it can be seen from Figure 2 (b) that e-CPA can correlate very well the solubility of $\mathrm{CH}_{4}$ in aqueous $\mathrm{NaCl}$ solution, and the solubility of $\mathrm{CH}_{4}$ decreases as the $\mathrm{NaCl}$ concentration increases. Combining with Figure S1, which presents the solubility of $\mathrm{CH}_{4}$ in aqueous $\mathrm{NaCl}$ solution at different salinity and temperatures, it is also observed that the solubility of $\mathrm{CH}_{4}$ decreases as temperature increases and pressure decreases, which is consistent with the literature ${ }^{106,107}$.

Figure S2 in the Support Information show the calculated gas solubility in aqueous $\mathrm{KCl}$ solution as a function of pressure at different salinity and temperatures. It can be seen, similar to the aqueous $\mathrm{NaCl}$ solution, that gas solubility in aqueous $\mathrm{KCl}$ solution decreases as temperature increases and as pressure decreases. As the molality of $\mathrm{KCl}$ increases, the 
gas solubility decreases significantly, which means that $\mathrm{KCl}$ has a salting-out effect on the gas solubilities of $\mathrm{CO}_{2}$ and $\mathrm{CH}_{4}$ in $\mathrm{H}_{2} \mathrm{O}$.

Figures 3 (a) and (b) present the modeling results of the solubilities of $\mathrm{CO}_{2}$ and $\mathrm{CH}_{4}$ in the aqueous $\mathrm{CaCl}_{2}$ solution, respectively. More modeling results of this system are presented in the Figures $\mathrm{S} 3$ in the Support Information. It can be seen that $\mathrm{CaCl}_{2}$ also has a significant salting-out effect on the solubilities of $\mathrm{CO}_{2}$ and $\mathrm{CH}_{4}$ in $\mathrm{H}_{2} \mathrm{O}$. The solubilities of both gases again increase as pressure increases. It is surprising that e-CPA can accurately capture the intersection of the solubility of $\mathrm{CO}_{2}$ in aqueous $\mathrm{CaCl}_{2}$ solution at $349.15 \mathrm{~K}$ and $374.15 \mathrm{~K}$. This indicates that the temperature dependence of the salt-outing effect will depend on the pressure, which can also be deduced from Figure 3 (a). The solubility of $\mathrm{CH}_{4}$ in aqueous $\mathrm{CaCl}_{2}$ solution decreases as temperature increases.

Figures 4 (a) and (b) show the comparison of the modeling results and experimental data of the solubilities of $\mathrm{CO}_{2}$ and $\mathrm{CH}_{4}$ in aqueous $\mathrm{MgCl}_{2}$ solution. Figure 4 (a) clearly shows that the solubility of $\mathrm{CO}_{2}$ decreases as temperature increases at a constant pressure and salinity, and the solubility of $\mathrm{CH}_{4}$ increases as pressure increases. A significant salting-out effect is also observed. It can be seen that e-CPA can accurately correlate the solubilities of $\mathrm{CO}_{2}$ and $\mathrm{CH}_{4}$ in aqueous $\mathrm{MgCl}_{2}$ solution. It is worth pointing out that the molality of $\mathrm{CaCl}_{2}$ and $\mathrm{MgCl}_{2}$ is smaller than that of $\mathrm{NaCl}$ and $\mathrm{KCl}$, and a more detailed comparison is given below. 


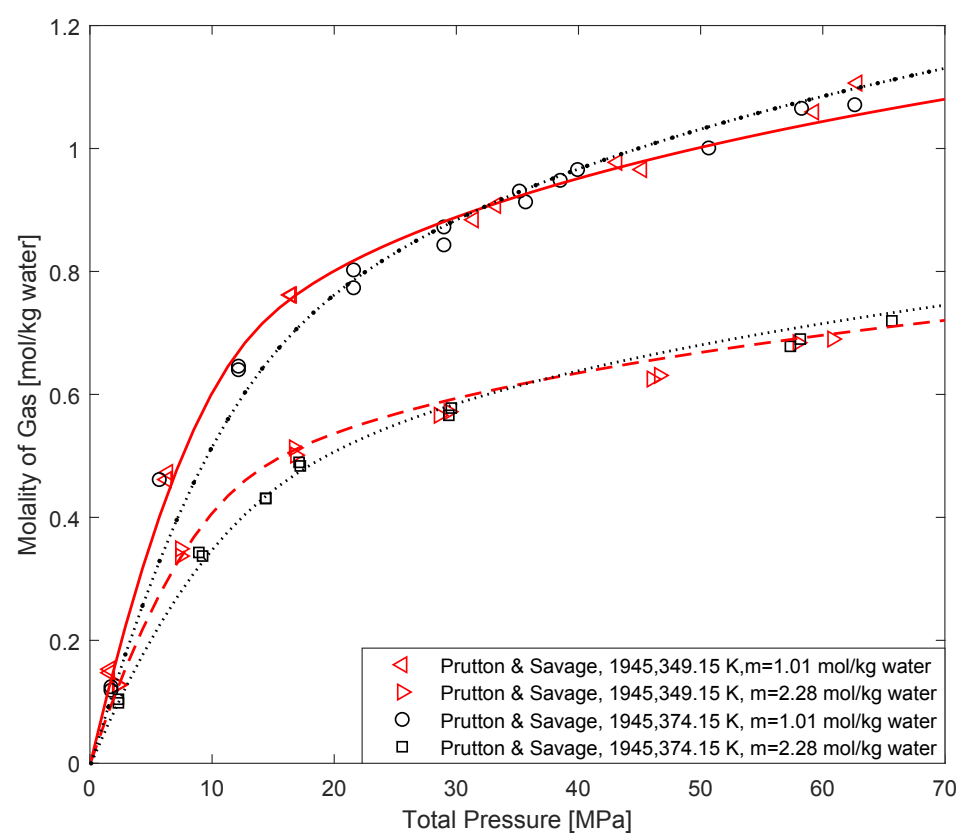

(a)

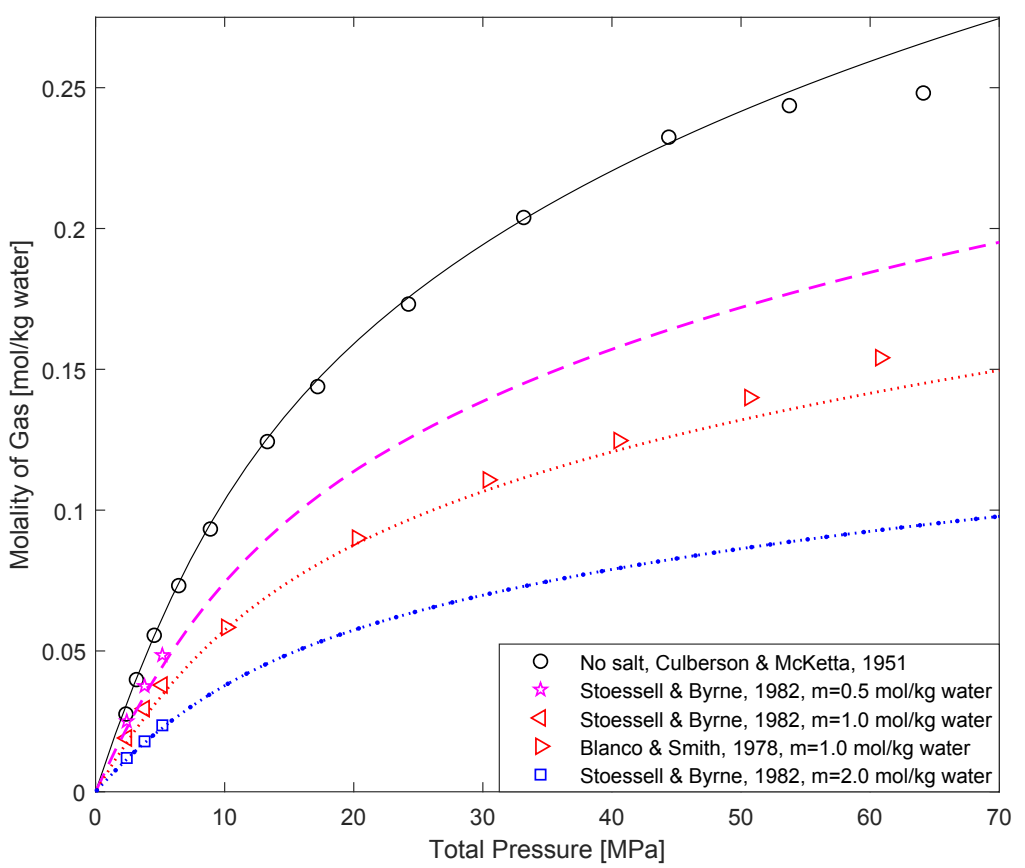

(b)

Figure 3. Comparison of the modelling results against the experimental data of the solubility of (a) $\mathrm{CO}_{2}$ in aqueous $\mathrm{CaCl}_{2}$ solution at $349.15 \mathrm{~K}$ and $374.15 \mathrm{~K}^{112}$; (b) $\mathrm{CH}_{4}$ in aqueous $\mathrm{CaCl}_{2}$ solution at $298.15 \mathrm{~K}^{66,107}$. 


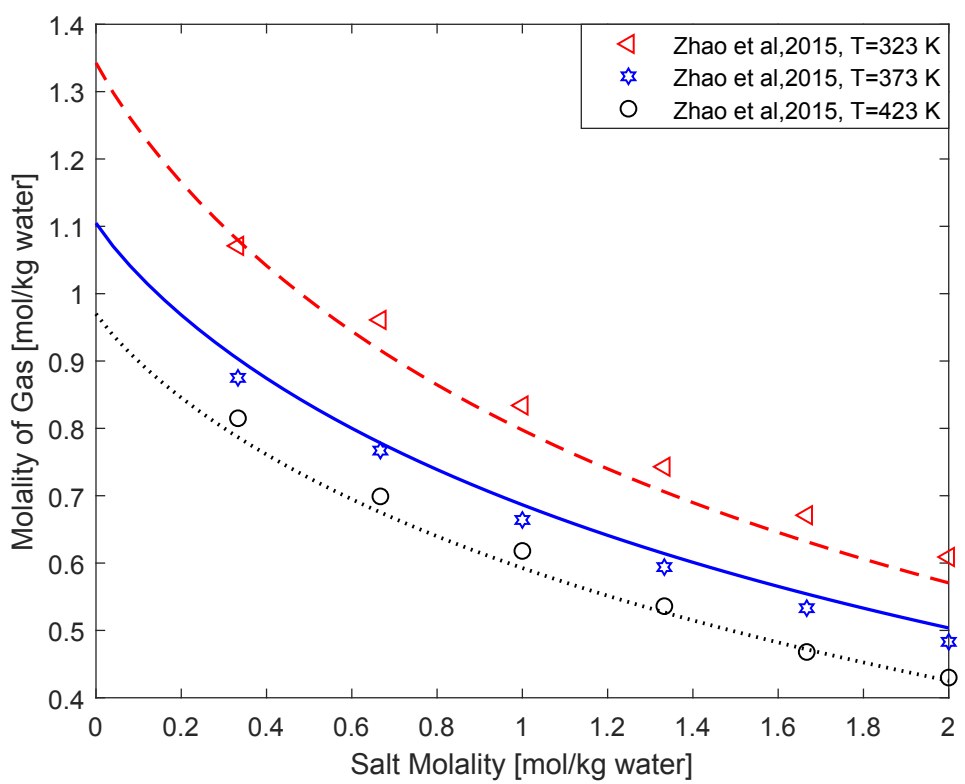

(a) Solubility of $\mathrm{CO}_{2}$ at $15 \mathrm{MPa}$

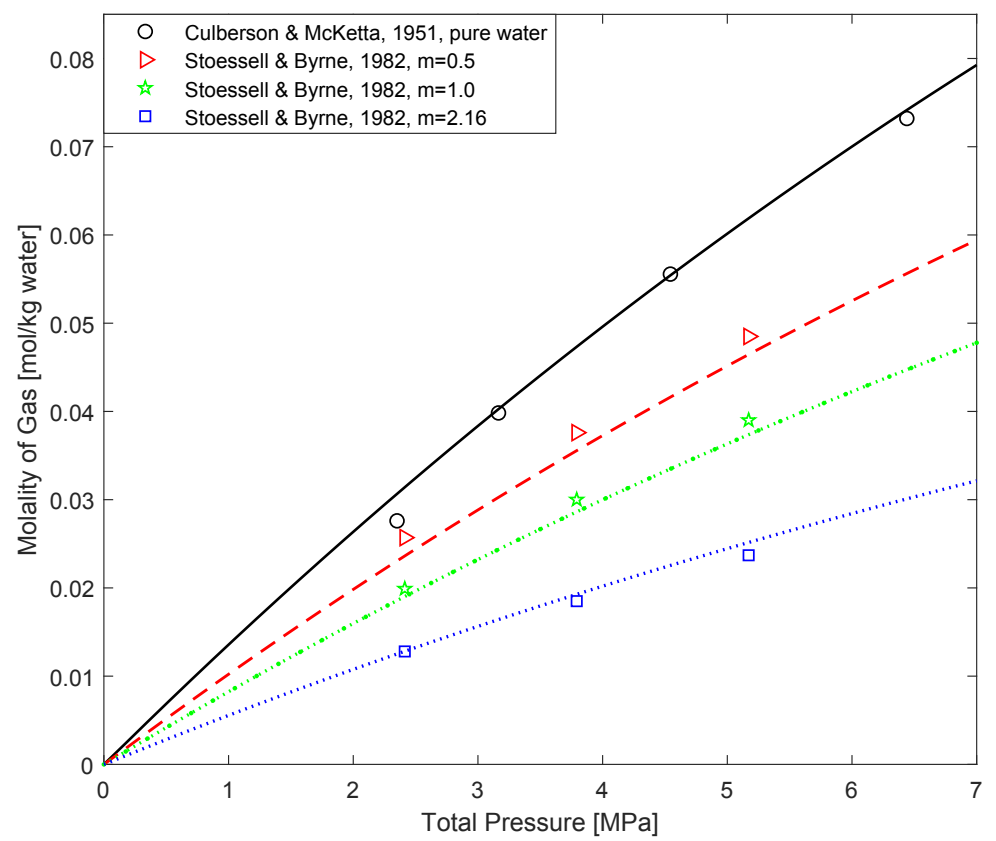

(b) Solubility of $\mathrm{CH}_{4}$ at $298.15 \mathrm{~K}$

Figure 4. Comparison of the modelling results against the experimental gas solubility in aqueous $\mathrm{MgCl}_{2}$ solution: (a) $\mathrm{CO}_{2}$ at $15 \mathrm{MPa}^{108}$; (b) $\mathrm{CH}_{4}$ at $298.15 \mathrm{~K}^{107}$. 
It can be seen from Figure 5 that e-CPA can satisfactorily correlate the solubility of $\mathrm{CO}_{2}$ in aqueous $\mathrm{Na}_{2} \mathrm{SO}_{4}$ solution, and a similar behavior of the intersection of different temperatures occurring at higher pressures might be suspected, as seen from Figure 3 (a).

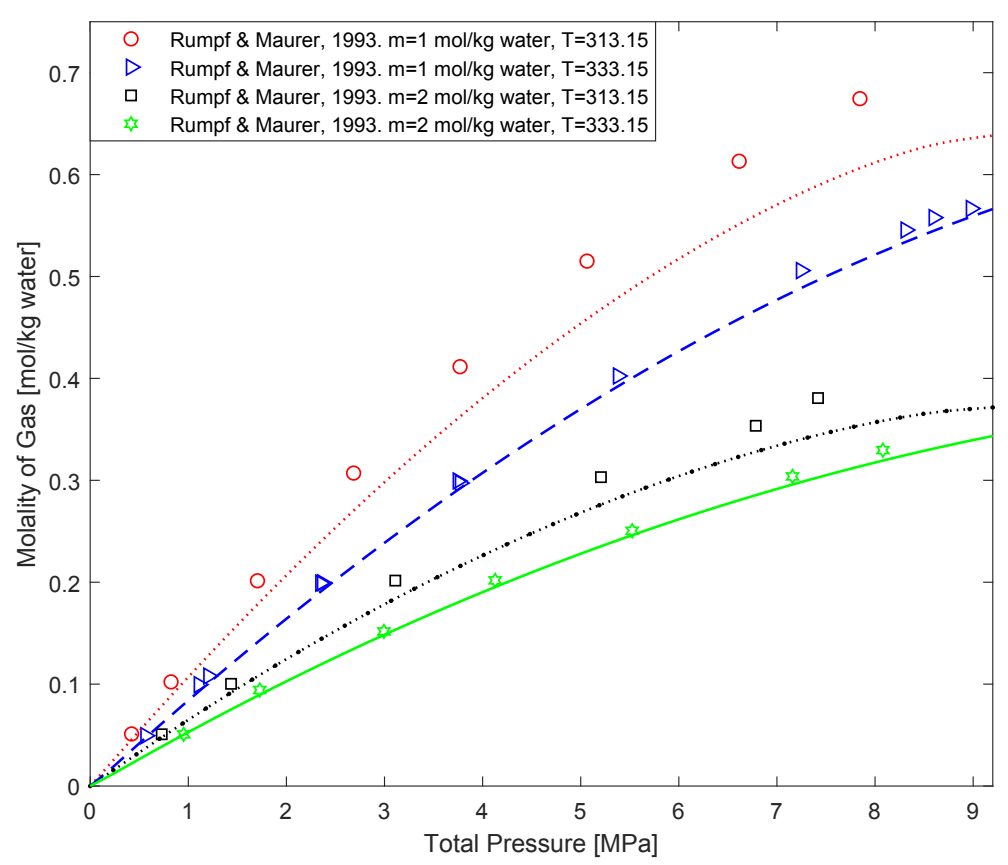

Figure 5. Comparison of the modelling results against the experimental solubility of $\mathrm{CO}_{2}{ }^{18}$ in aqueous $\mathrm{Na}_{2} \mathrm{SO}_{4}$ solution.

\subsection{Extension to Multi-salt Systems}

In this work, within the e-CPA framework, there are no binary interaction parameters between ions, and the parameters for single $\mathrm{H}_{2} \mathrm{O}$-salt and salt-gas can be applied to multisalt solutions without new adjustable parameters, provided that the anion and cations are compatible, i.e. having the same cation or same anion. Maribo-Mogensen et al. ${ }^{49}$ used the binary interaction parameters of from aqueous single-salt solutions to calculate the osmotic coefficients of aqueous multi-salt solutions $\left(\mathrm{KCl}+\mathrm{NaCl}, \quad \mathrm{Na}_{2} \mathrm{SO}_{4}+\mathrm{NaCl}\right.$, 
$\mathrm{NaCl}+\mathrm{KCl}+\mathrm{MgCl}_{2}$ ) and reasonably good predictions were obtained in all cases. Table 4 lists the predictions of the osmotic coefficients and water activity for aqueous multi-salt solutions. It can be seen from Table 4 that e-CPA can give good agreement with water activity and osmotic coefficients of aqueous multi-salt solutions, except for the system $\mathrm{H}_{2} \mathrm{O}-\mathrm{CaCl}_{2}-\mathrm{MgCl}_{2}$. The large deviation of this system is because the salt molality goes far beyond the correlation range, or saying the maximum effective molality range, and the ionpairing effect may have become an important contribution, which is not considered in eCPA. It can be concluded that the model with single-salt (cation/anion) $-\mathrm{H}_{2} \mathrm{O}$ interaction parameters can be used for aqueous multi-salt solutions.

Table 4. e-CPA performance for osmotic coefficients and water activity of aqueous multisalt solutions.

\begin{tabular}{llllll}
\hline \multirow{2}{*}{ Salt } & $\mathrm{T}[\mathrm{K}]$ & $\mathrm{I}_{\max }{ }^{\mathrm{a}}$ & $\mathrm{Np}$ & \multicolumn{2}{c}{$\mathrm{AAD}[\%]$} \\
\cline { 5 - 6 } & & {$[\mathrm{mol} / \mathrm{kg}$ water $]$} & & & $a_{W}{ }^{\mathrm{b}}$ \\
$\mathrm{NaCl}+\mathrm{KCl}$ & 298.15 & $12^{115,116}$ & 57 & 2.3 & - \\
& & $14.6^{117}$ & 1 & - & 0.3 \\
$\mathrm{KCl}+\mathrm{CaCl}_{2}$ & 298.15 & $5^{118}$ & 30 & 3.4 & - \\
$\mathrm{CaCl}+\mathrm{MgCl}_{2}$ & $298.15-323.15$ & $17.0^{119}$ & 71 & 9.1 & - \\
$\mathrm{NaCl}+\mathrm{KCl}+\mathrm{MgCl}_{2}$ & 298.15 & $14.01^{117}$ & 2 & - & 2.7 \\
\hline
\end{tabular}

a. $\mathrm{I}_{\max }$ is the maximum ionic strength; $\mathrm{b} . a_{W}$ is the water activity. 
Compared to the solubility data of $\mathrm{CO}_{2}$ in aqueous single-salt solutions, the sources of the solubility data in aqueous multi-salt solutions are much limited, and the predictions are presented in Table 5 and Figures 6-8. There are only few scatter data ${ }^{120}$ of the solubility $\mathrm{CH}_{4}$ in aqueous multi-salt solutions, Table S5 of Supporting Information lists the results of these scatter data $(\mathrm{AAD}=5.9 \%)$. It can be seen from Tables 5 and $\mathrm{S} 5$ and Figures $6-8$ that e-CPA can very reasonably predict the gas solubility in aqueous solutions over a wide range of salt mixtures. It needs to be pointed out that Liu et al. ${ }^{101}$ did not clearly state which scale they used to report the solubility data, which are assumed to be salt-free in our modeling.

Table 5. Modelling performance of e-CPA for the solubility of $\mathrm{CO}_{2}$ in aqueous multi-salt solutions with the binary interaction parameters from Table 3.

\begin{tabular}{llllll}
\hline Salts & $\mathrm{T}[\mathrm{K}]$ & $\mathrm{P}[\mathrm{MPa}]$ & $\mathrm{I}^{\mathrm{a}}$ & $\mathrm{Np}$ & $\mathrm{AAD}$ \\
& & & & & {$[\%]$} \\
\hline $\mathrm{NaCl}+\mathrm{KCl}$ & $308.9-424.67$ & $1.07-17.16$ & $1.053,1.69$ & $22^{101,110}$ & 4.8 \\
\hline $\mathrm{NaCl}+\mathrm{CaCl}_{2}$ & 318.15 & $2.46-16.02$ & 2.45 & $8^{101}$ & 4.2 \\
\hline $\mathrm{KCl}+\mathrm{CaCl}_{2}$ & 318.15 & $2.09-15.87$ & 2.25 & $8^{101}$ & 5.0 \\
\hline $\mathrm{NaCl}+\mathrm{KCl}^{2} \mathrm{CaCl}_{2}$ & $308.15-328.15$ & $1.34-15.85$ & $1.00-3.20$ & $75^{101}$ & 6.1 \\
\hline $\mathrm{NaCl}+\mathrm{KCl}+\mathrm{CaCl}_{2}+$ & 297 & $0.52-14.12$ & $1.70,2.65$ & $84^{121}$ & 15.7 \\
$\mathrm{MgCl}_{2}$ & & & & & \\
\hline
\end{tabular}

a. ionic strength [mol/kg water]; b. for gas solubility in molality. 


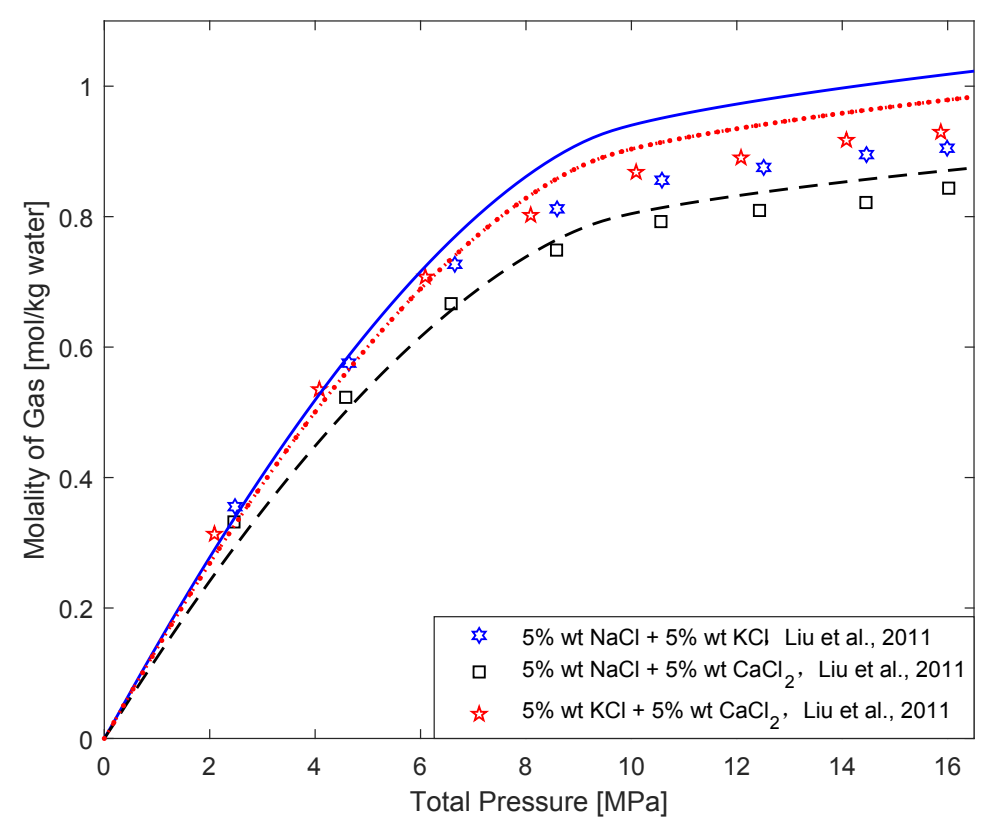

Figure 6. Comparison of the modelling results against the experimental solubility of $\mathrm{CO}_{2}{ }^{101}$ in aqueous solutions of two salts at $\mathrm{T}=318.15 \mathrm{~K}$. The weight percentage of the two salts are given in the Figure legend.

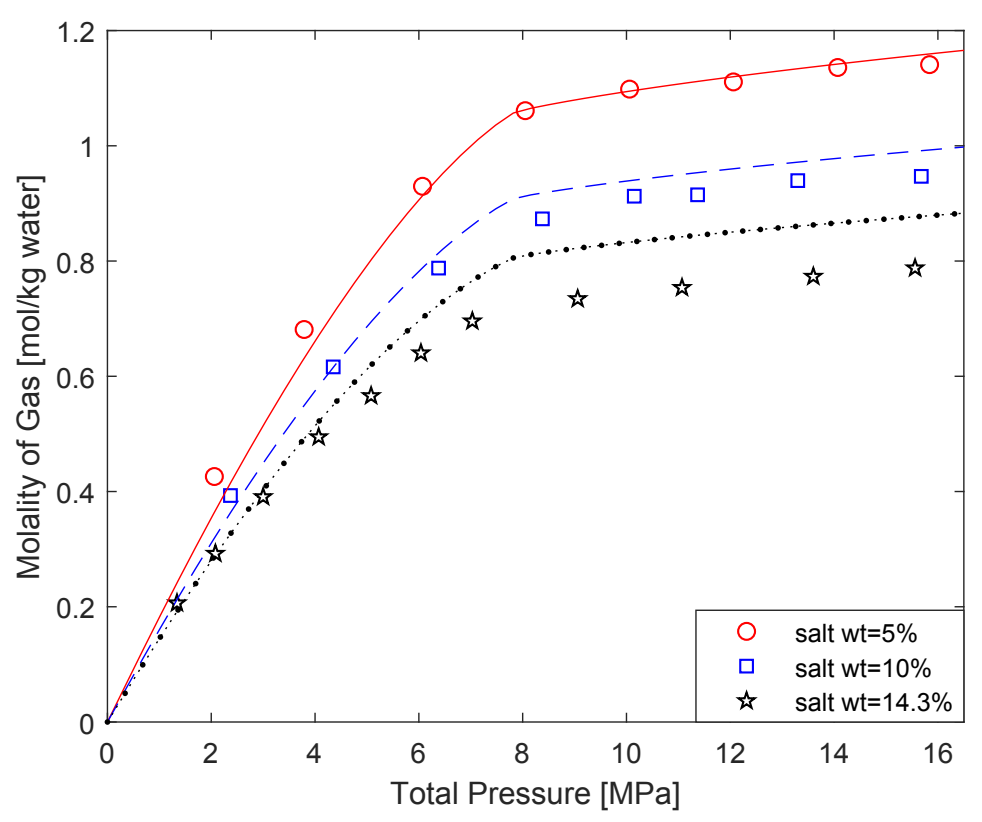

Figure 7. Comparison of the modelling results against the experimental solubility of $\mathrm{CO}_{2}{ }^{101}$ in the aqueous solutions of three salts at $\mathrm{T}=308.15 \mathrm{~K}$ and different mass fraction of salts. The weight ratio of $\mathrm{NaCl}, \mathrm{KCl}$ and $\mathrm{CaCl}_{2}$ is $1: 1: 1$. 


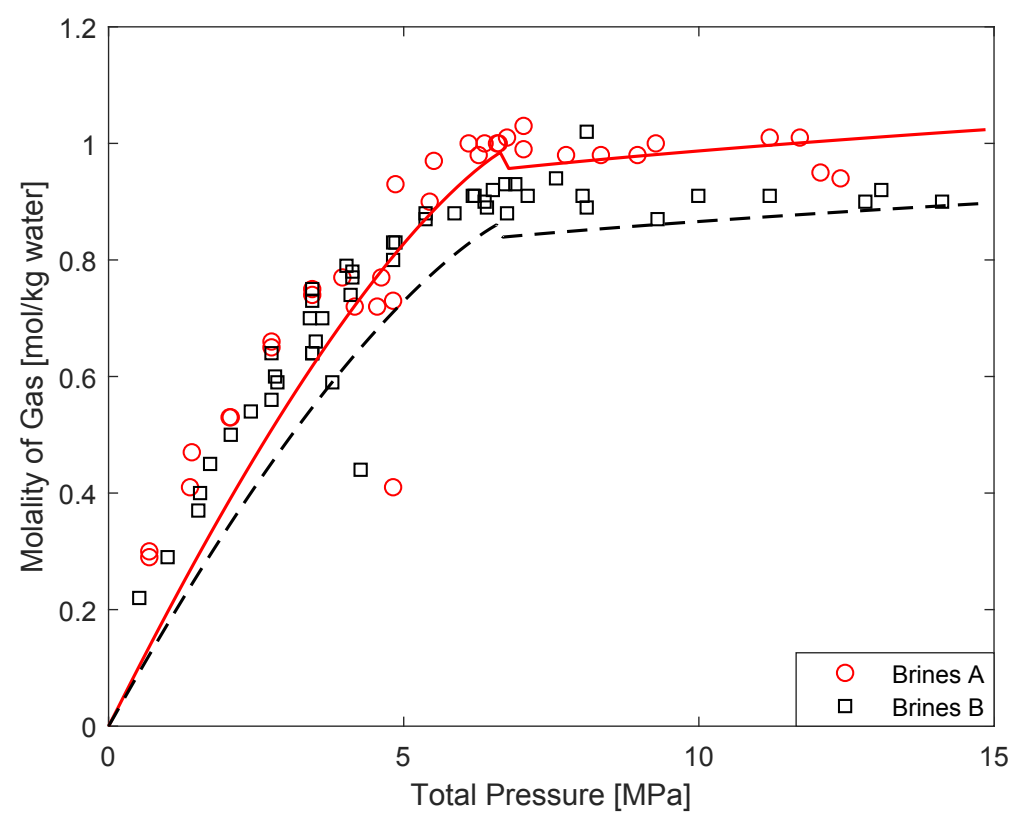

Figure 8. Comparison of the modelling results against the experimental solubility of $\mathrm{CO}_{2}{ }^{121}$ in two aqueous salt solutions: Brines $\mathrm{A}\left(\mathrm{mNaCl}=1.001, \mathrm{mKCl}=0.101, \mathrm{mCaCl}_{2}=0.100\right.$, $\mathrm{mMgCl}_{2}=0.100$, all in $\mathrm{mol} / \mathrm{kg}$ water $)$ Brines $\mathrm{B} \quad(\mathrm{mNaCl}=1.396, \quad \mathrm{mKCl}=0.047$, $\mathrm{mCaCl}_{2}=0.339, \mathrm{mMgCl}_{2}=0.061$, all in $\mathrm{mol} / \mathrm{kg}$ water) at $297 \mathrm{~K}$.

\subsection{Discussion}

\subsubsection{Salting Effects of Different Salts}

It is known that different salts have different salting-out effects, and the ion concentration and ion charge are believed the two main factors. The studies of the ion hydration and ion$\mathrm{H}_{2} \mathrm{O}$ molecule interactions ${ }^{122,123}$ demonstrated that ions with smaller size and higher charge density bind $\mathrm{H}_{2} \mathrm{O}$ molecules stronger, which weakens the capacity of helping solvent trap dissolved gas molecules. Anions usually have larger ionic radii than cations, so the hydration of cations is usually much stronger than that of anions ${ }^{124}$. In order to analyze the 
salting-out effect of different salts in detail, the solubilities of $\mathrm{CO}_{2}$ and $\mathrm{CH}_{4}$ in different aqueous salt solutions are compared in Figures 9 and 10.

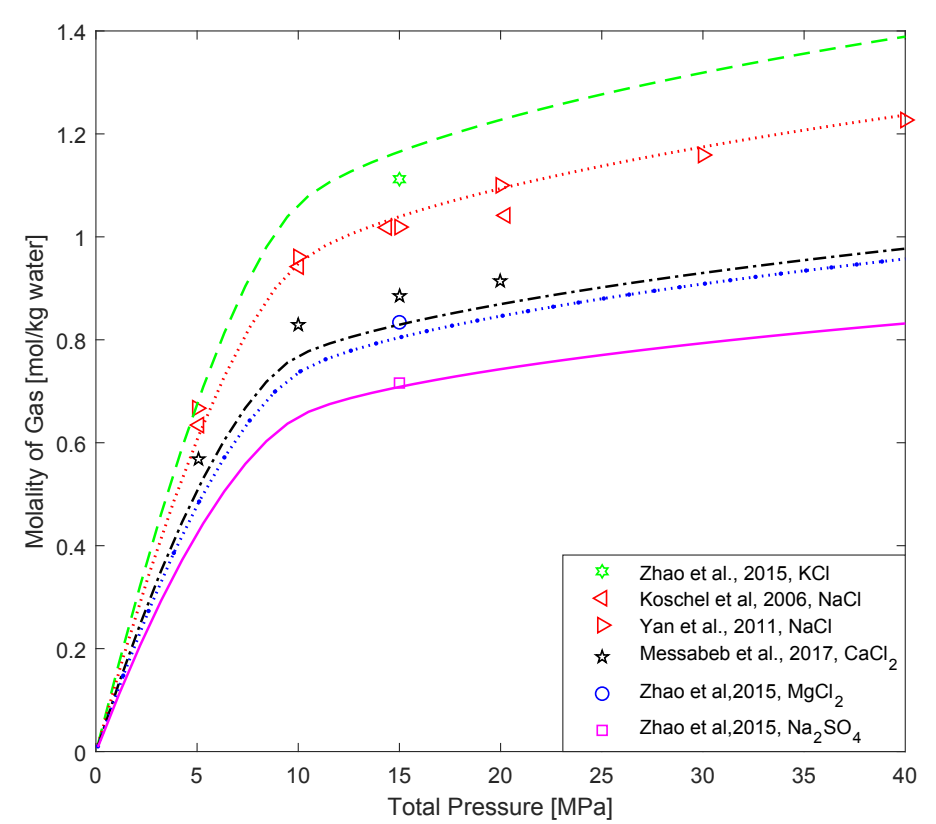

(a) different salts with same molality $(1.0 \mathrm{~mol} / \mathrm{kg}$ water $)$

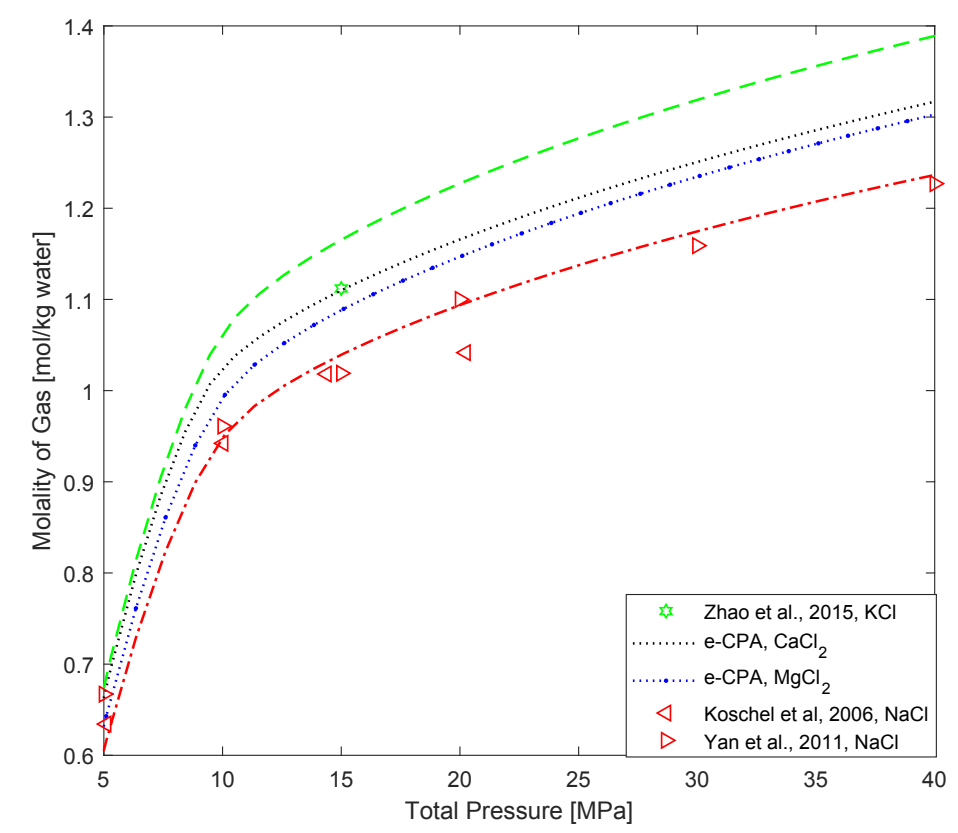

(b) different salts with same ionic strength $(1.0 \mathrm{~mol} / \mathrm{kg}$ water $)$

Figure 9. Comparison of the solubility of $\mathrm{CO}_{2}$ in aqueous solutions of different salts at $323.15 \mathrm{~K}^{62,65,108,111}$. 
It can be seen from Figure 9 (a) that different salts exhibit different salting-out effects, and the salting-out effects on $\mathrm{CO}_{2}$ follow a sequence of $\mathrm{KCl}<\mathrm{NaCl}<\mathrm{CaCl}_{2} \approx \mathrm{MgCl}_{2}<\mathrm{Na}_{2} \mathrm{SO}_{4}$ with the same molality. This is consistent with the findings from Jacob and Saylor ${ }^{121}$. $\mathrm{Na}_{2} \mathrm{SO}_{4}$ shows the strongest salting-out effect on the solubility of $\mathrm{CO}_{2}$ mainly because 1 mol Na $\mathrm{SO}_{4}$ has $2 \mathrm{~mol} \mathrm{Na}^{+}$, and this is similar to the salting-out effect on the solubility of amino acids in water ${ }^{125}$.

For $\mathrm{KCl}, \mathrm{NaCl}, \mathrm{CaCl}_{2}$ and $\mathrm{MgCl}_{2}$, the salting-out effect is significantly greater with divalent cations, because the ion charge is more important than ion size in relation to the salting-out effect in these aqueous solutions with the same salt molality.

$\mathrm{KCl}$ shows the weakest salting-out effect, mainly because $\mathrm{K}^{+}$has a low charge density and it binds $\mathrm{H}_{2} \mathrm{O}$ weakly, and there are more intervals to accommodate gas molecules ${ }^{101,108,122,123}$. The low charge density of $\mathrm{K}^{+}$comes from that $\mathrm{K}^{+}$, with charge of ${ }^{`}+1$ ', has a relatively bigger size than $\mathrm{Na}^{+}, \mathrm{Mg}^{2+}$ and $\mathrm{Ca}^{2+}$ (Pauling Radius: $\mathrm{K}^{+}-1.33 \AA$; $\mathrm{Na}^{+}-$ $0.95 \AA ; \mathrm{Ca}^{2+}-0.99 \AA ; \mathrm{Mg}^{2+}-0.65 \AA$ ). Kiepe et al. ${ }^{10}$ observed that the salting-out effect of $\mathrm{KCl}$ is smaller than that of $\mathrm{NaCl}$ on the solubility of $\mathrm{CO}_{2}$.

Figure 9 (b) shows that the salting-out effects on $\mathrm{CO}_{2}$ follow a sequence of $\mathrm{KCl}<\mathrm{CaCl}_{2}<\mathrm{MgCl}_{2}<\mathrm{NaCl}$ with the same ionic strength, and this is consistent with the work of Zhao et al. ${ }^{108}$.

It can also be observed from both Figures 9 (a) and (b) that $\mathrm{MgCl}_{2}$ and $\mathrm{CaCl}_{2}$ have similar salting-out effects. Portier et al. ${ }^{8}$ pointed out that the salting-out effect of $\mathrm{CaCl}_{2}$ or $\mathrm{MgCl}_{2}$ on the solubility of $\mathrm{CO}_{2}$ in aqueous solutions is lower than that of $\mathrm{NaCl}$ of equivalent ionic 
strength, because $\mathrm{Ca}^{2+}$ and $\mathrm{Mg}^{2+}$ tended to form ion pairs easier.

Figure 10 shows that the salting-out effects on-the solubility of $\mathrm{CH}_{4}$ follow a sequence of $\mathrm{KCl}<\mathrm{NaCl}<\mathrm{MgCl}_{2} \approx \mathrm{CaCl}_{2}$ with the same molality, and $\mathrm{MgCl}_{2}$ and $\mathrm{CaCl}_{2}$ have similar salting-out effects.

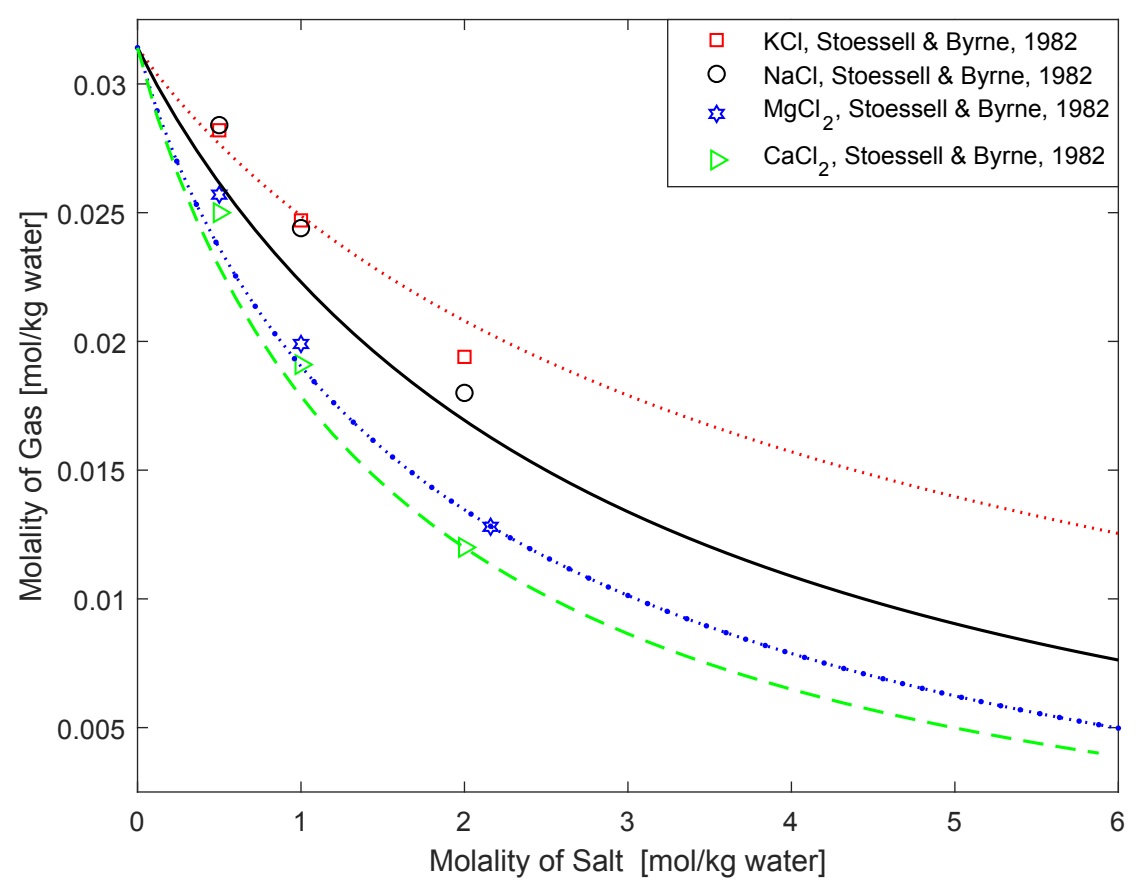

Figure 10. Comparison of the solubility of $\mathrm{CH}_{4}$ in different electrolyte aqueous solutions with the same molality $(1.0 \mathrm{~mol} / \mathrm{kg}$ water $)$ at $298.15 \mathrm{~K}$ and $\mathrm{P}=2.41 \mathrm{MPa}^{107}$. 


\subsubsection{Comparison with Literature Electrolyte EOS}

Table 6 shows a comparison of different electrolyte EOS for gas solubility calculations in aqueous solutions of inorganic salts. In these electrolyte EOS, Zuo and Guo ${ }^{40}$, Sun and Dubessy ${ }^{45}$, Tan et al. ${ }^{42}$, and $\mathrm{Ji}$ et $\mathrm{al}^{48}$ assumed that the dielectric constant of electrolyte solution is equal to that of the solvent. Other models ${ }^{37-39,41,43,46,47}$ take the effect of salt presence on dielectric constant into account. e-CPA uses a theoretical model for dielectric constant calculation, which eliminates the kinetic depolarization. Søreide and Whitson ${ }^{37}$, Aasberg-Petersen et al. ${ }^{39}$, Haghighi et al. ${ }^{41}$, and Sun and Dubessy ${ }^{44,45}$ did not explicitly take the ion solvation contribution into account, while other models included the ion solvation contribution via the Born term, which is believed important for salting-out effects and thermodynamic modeling of other properties and behavior. Temperature dependency of ion-gas interactions is used in some works, and the most studied system is $\mathrm{H}_{2} \mathrm{O}-\mathrm{NaCl}-\mathrm{CO}_{2}$. Both Harvey and Prausnitz ${ }^{38}$ and Rozmus et al. ${ }^{46}$ stated that their models can be applied to multi-salt solutions flexibly. To be best of our knowledge, however, no electrolyte EOS has been really applied for calculating the gas solubility in aqueous multi-salt solutions. In this work, e-CPA has been extended to multi-salt systems without new adjustable parameters. 
Table 6. Summary of modelling of gas solubility in aqueous solutions with electrolyte EOS.

\begin{tabular}{|c|c|c|c|c|}
\hline Ref & EOS & Elect. Terms & Ion-Gas IPs & Salts \\
\hline \multirow{3}{*}{37} & & & $\mathrm{~N}_{2}: 4\left(\mathrm{~T}-\mathrm{dep}^{\mathrm{a}}\right)$ & \\
\hline & PR & None & $\mathrm{CO}_{2}: 6$ (T-dep) & $\mathrm{NaCl}$ \\
\hline & & & $\mathrm{H}_{2} \mathrm{~S}: 2$ (T-dep) & \\
\hline 38 & P-LJ b & MSA+Born & $1\left(\mathrm{~T}\right.$-ind $\left.{ }^{\mathrm{c}}\right)$ & $\mathrm{NaCl}, \mathrm{CaCl}_{2}$ \\
\hline 39 & ALS & $\mathrm{DH}$ & 1 (T-ind) & $\mathrm{NaCl}, \mathrm{CaCl}_{2}$ \\
\hline 40 & PT & $\mathrm{DH}$ & 1 (T-ind) & $\mathrm{NaCl}, \mathrm{CaCl}_{2}$ \\
\hline \multirow{2}{*}[\mathrm{TW},{}^{49}]{$^{\mathrm{d}}$} & CPA & $\mathrm{DH}+\mathrm{Born}$ & 3 (T-dep) & \\
\hline & & & & $\mathrm{Na}_{2} \mathrm{SO}_{4}$, multi-salt \\
\hline 41 & CPA & $\mathrm{DH}$ & 5 (T-dep) & $\mathrm{NaCl}, \mathrm{CaCl}_{2}, \mathrm{KCl}, \mathrm{MgCl}_{2}$ \\
\hline 42 & $\mathrm{CPA}$ & PMSA+Born & 3 (T-dep) & $\mathrm{NaCl}$ \\
\hline 43 & CPA & MSA+Born & 3 (T-dep) & $\mathrm{NaCl}$ \\
\hline 42 & PC-SAFT & PMSA & 3 (T-dep) & $\mathrm{NaCl}$ \\
\hline 45 & SAFT-LJ & MSA & 3 (T-dep) & $\mathrm{NaCl}$ \\
\hline 46 & $\begin{array}{l}\text { PPC- } \\
\text { SAFT }\end{array}$ & MSA+Born & Neglected & $\mathrm{NaCl}$ \\
\hline 47 & SAFT-VR & MSA+Born & 3 (T-dep) & $\mathrm{NaCl}$ \\
\hline 48 & SAFT1 & RPM & 1 (T-ind) & $\mathrm{NaCl}$ \\
\hline
\end{tabular}




\begin{abstract}
a. T-dep: Temperature-dependent; b. Short-range perturbed term with Lennard-Jones potential; c. T-ind: Temperature-independent; d. TW: This work;
\end{abstract}

Most of the electrolyte EOS listed in Table 6 perform satisfactorily at low salt molality. Harvey-Prausnitz model ${ }^{38}$ overestimates $\mathrm{CO}_{2}$ solubility $(\mathrm{AAD} \approx 10-20 \%$ ) at high salt molality. The model (ALS+DH) proposed by Aasberg-Petersen et al. ${ }^{39}$ slightly overpredicts gas solubility at high salt molality, and the deviation between calculated and experimental values may in certain cases be $10-15 \%$, while the deviations are somewhat larger for the aqueous $\mathrm{CaCl}_{2}$ solution. The MPT $\mathrm{EOS}^{40}$ shows inaccurate results for the $\mathrm{CO}_{2}$ solubility in aqueous $\mathrm{NaCl}$ solution, and it can only be applied over narrow temperature ranges, probably because the temperature-dependent parameters have not been used. Although the Søreide-Whitson mode ${ }^{37}$ is relatively simple, it uses two different sets of interaction parameters. Thus, it is essentially an inconsistent thermodynamic model, and it cannot satisfactorily describe the solubility of $\mathrm{CO}_{2}$ in aqueous solutions with high salt molality (by more than $20 \%$ at $50{ }^{\circ} \mathrm{C}$ in $\mathrm{NaCl}$ solution with molality $=2 \mathrm{~mol} / \mathrm{kg}$ water, and at pressures=100 bar). Tan et al.'s mode ${ }^{42}$ (CPA+PMSA) performs poorly at high molality and pressure. Courtial et al. ${ }^{43}$ used some unreliable experimental data for modelling, and the deviations of solubility are large. Sun and Dubessy 44,45 applied their model (SAFT$\mathrm{LJ}+\mathrm{MSA}$ ) to calculate the solubility of $\mathrm{CO}_{2}$ in aqueous $\mathrm{NaCl}$ solution (range from 273 to $573 \mathrm{~K}$, from 0 to $1000 \mathrm{bar}$, and from 0 to $6 \mathrm{~mol} / \mathrm{kg} \mathrm{NaCl}$ ). The deviation for the solubility of $\mathrm{CO}_{2}$ with $\mathrm{NaCl}$ molality lower than $4 \mathrm{~mol} / \mathrm{kg}$ is $3 \%$. Schreckenberg et al. ${ }^{47}$ stated that 
the performance of their model for calculating the solubility of $\mathrm{CO}_{2}$ is not good at high salt molality. It is easy to notice that the solubility of $\mathrm{CO}_{2}$ is higher than that of $\mathrm{CH}_{4}$ in the same system under the same condition, which as mentioned above is probably because of the $\mathrm{CO}_{2}$ dissociation. The chemical equilibria have not been taken into account in this work. For modelling the solubility of $\mathrm{CO}_{2}$ with an electrolyte EOS considering chemical equilibria, readers might be referred to ${ }^{126,127}$. It would be interesting to make a fair and systematic comparison for these two approaches in term of easiness of parameterization, predictive capability and flexibility of extension to multi-salt solutions.

\section{Conclusion}

The solubilities of $\mathrm{CO}_{2}$ and $\mathrm{CH}_{4}$ in several aqueous solutions of inorganic salts have been studied systematically with the e-CPA EOS. In this work. It can be concluded that e-CPA gives accurate agreements with the experimental solubility data of $\mathrm{H}_{2} \mathrm{O}$-gas and $\mathrm{H}_{2} \mathrm{O}$-salt binary systems. With temperature-dependent ion-gas interaction parameters, e-CPA gives excellent agreement with the experimental gas solubility data over wide ranges of temperature, pressure and salt molality. e-CPA also predicts satisfactory agreements with the experimental gas solubility data in aqueous multi-salt solutions, without new adjustable parameters. Moreover, e-CPA shows a good performance on the salting-out effects from temperature and pressure as well as from ion size, charge density and salt concentration. 


\title{
Acknowledgments
}

This work is supported by the Department of Chemical and Biochemical Engineering, Technical University of Denmark and China Scholarship Council (No. 201608320224).

\section{Supporting Information}

Support Information consists of three parts: Properties and pure component parameters for e-CPA; Modelling performance of mean ionic activity coefficients and osmotic coefficients for water-salt binary systems; Modelling performance for gas solubility in aqueous single-salt and multi-salt solutions.

\author{
Author Information \\ Corresponding author: \\ E-mail address: xlia@kt.dtu.dk, Tel.: 0045-4525 2877.
}




\section{Reference}

(1) Fyfe, W. S.: Fluids In The Earth's Crust: Their Significance In Metamorphic, Tectonic And Chemical Transport Process; Elsevier, 2012; Vol. 1.

(2) Duan, Z.; Møller, N.; Greenberg, J.; Weare, J. H. The prediction of methane solubility in natural waters to high ionic strength from 0 to $250 \mathrm{C}$ and from 0 to 1600 bar. Geochimica et Cosmochimica Acta 1992, 56, 1451-1460.

(3) Sloan Jr, E. D.; Koh, C. A.: Clathrate hydrates of natural gases; CRC press, 2007.

(4) Roedder, E. The fluids in salt. American Mineralogist 1984, 69, 413-439.

(5) Millero, F. J. Thermodynamics of the carbon dioxide system in the oceans. Geochimica et Cosmochimica Acta 1995, 59, 661-677.

(6) Li, Y. K.; Nghiem, L. X. Phase equilibria of oil, gas and water/brine mixtures from a cubic equation of state and Henry's law. The Canadian Journal of Chemical Engineering 1986, 64, 486-496.

(7) Nighswander, J. A.; Kalogerakis, N.; Mehrotra, A. K. Solubilities of carbon dioxide in water and $1 \mathrm{wt} . \%$ sodium chloride solution at pressures up to $10 \mathrm{MPa}$ and temperatures from 80 to 200. degree. C. Journal of Chemical and Engineering Data 1989, 34, 355-360.

(8) Portier, S.; Rochelle, C. Modelling CO2 solubility in pure water and NaCl-type waters from 0 to $300 \mathrm{C}$ and from 1 to 300 bar: Application to the Utsira Formation at Sleipner. Chemical Geology 2005, 217, 187-199.

(9) Li, J.; Topphoff, M.; Fischer, K.; Gmehling, J. Prediction of gas solubilities in aqueous electrolyte systems using the predictive Soave- Redlich- Kwong model. Industrial \& 
engineering chemistry research 2001, 40, 3703-3710.

(10)Kiepe, J.; Horstmann, S.; Fischer, K.; Gmehling, J. Experimental determination and prediction of gas solubility data for $\mathrm{CO} 2+\mathrm{H} 2 \mathrm{O}$ mixtures containing $\mathrm{NaCl}$ or $\mathrm{KCl}$ at temperatures between 313 and $393 \mathrm{~K}$ and pressures up to $10 \mathrm{MPa}$. Industrial \& Engineering Chemistry Research 2002, 41, 4393-4398.

(11)García, A. V.; Thomsen, K.; Stenby, E. H. Prediction of mineral scale formation in geothermal and oilfield operations using the Extended UNIQUAC model: Part II. Carbonate-scaling minerals. Geothermics 2006, 35, 239-284.

(12) Sørensen, H.; Pedersen, K. S.; Christensen, P. L. Modeling of gas solubility in brine. Organic Geochemistry 2002, 33, 635-642.

(13) Spycher, N.; Pruess, K.; Ennis-King, J. CO2-H2O mixtures in the geological sequestration of CO2. I. Assessment and calculation of mutual solubilities from 12 to 100 C and up to 600 bar. Geochimica et cosmochimica acta 2003, 67, 3015-3031.

(14)Spycher, N.; Pruess, K. CO2-H2O Mixtures in the Geological Sequestration of CO2. II. Partitioning in Chloride Brines at $12-100 \mathrm{C}$ and up to 600 bar. Geochimica et Cosmochimica Acta 2005, 69, 3309-3320.

(15)Spycher, N.; Pruess, K. A phase-partitioning model for CO 2-brine mixtures at elevated temperatures and pressures: application to $\mathrm{CO} 2$-enhanced geothermal systems. Transport in porous media 2010, 82, 173-196.

(16)Rumpf, B.; Nicolaisen, H.; Öcal, C.; Maurer, G. Solubility of carbon dioxide in aqueous solutions of sodium chloride: experimental results and correlation. Journal of 
solution chemistry 1994, 23, 431-448.

(17)Duan, Z.; Sun, R. An improved model calculating CO2 solubility in pure water and aqueous $\mathrm{NaCl}$ solutions from 273 to $533 \mathrm{~K}$ and from 0 to 2000 bar. Chemical geology 2003, 193, 257-271.

(18)Rumpf, B.; Maurer, G. An experimental and theoretical investigation on the solubility of carbon dioxide in aqueous solutions of strong electrolytes. Berichte der Bunsengesellschaft fuer physikalische chemie 1993, 97, 85-97.

(19)Zhao, H.; Fedkin, M. V.; Dilmore, R. M.; Lvov, S. N. Carbon dioxide solubility in aqueous solutions of sodium chloride at geological conditions: Experimental results at $323.15,373.15$, and $423.15 \mathrm{~K}$ and 150 bar and modeling up to $573.15 \mathrm{~K}$ and 2000 bar. Geochimica et Cosmochimica Acta 2015, 149, 165-189.

(20)Masoudi, R.; Tohidi, B.; Danesh, A.; Todd, A. C. A new approach in modelling phase equilibria and gas solubility in electrolyte solutions and its applications to gas hydrates. Fluid Phase Equilibria 2004, 215, 163-174.

(21)Pérez-Salado Kamps, Á.; Meyer, E.; Rumpf, B.; Maurer, G. Solubility of CO2 in aqueous solutions of $\mathrm{KCl}$ and in aqueous solutions of $\mathrm{K} 2 \mathrm{CO} 3$. Journal of Chemical \& Engineering Data 2007, 52, 817-832.

(22)Yan, Y.; Chen, C.-C. Thermodynamic modeling of $\mathrm{CO} 2$ solubility in aqueous solutions of $\mathrm{NaCl}$ and $\mathrm{Na} 2 \mathrm{SO} 4$. The Journal of Supercritical Fluids 2010, 55, 623-634.

(23)Duan, Z.; Møller, N.; Weare, J. H. An equation of state for the CH4-CO2-H2O system: II. Mixtures from 50 to $1000 \mathrm{C}$ and 0 to 1000 bar. Geochimica et Cosmochimica Acta 1992, 
$56,2619-2631$.

(24)Duan, Z.; Møller, N.; Weare, J. H. An equation of state for the CH4-CO2-H2O system:

I. Pure systems from 0 to $1000 \mathrm{C}$ and 0 to 8000 bar. Geochimica et Cosmochimica Acta 1992, 56, 2605-2617.

(25)Peng, D.-Y.; Robinson, D. B. A new two-constant equation of state. Industrial \& Engineering Chemistry Fundamentals 1976, 15, 59-64.

(26)Soave, G. Equilibrium constants from a modified Redlich-Kwong equation of state. Chemical engineering science 1972, 27, 1197-1203.

(27)Redlich, O.; Kwong, J. N. On the thermodynamics of solutions. V. An equation of state. Fugacities of gaseous solutions. Chemical reviews 1949, 44, 233-244.

(28)Avlonitis, D.; Danesh, A.; Todd, A. Prediction of VL and VLL equilibria of mixtures containing petroleum reservoir fluids and methanol with a cubic EoS. Fluid Phase Equilibria 1994, 94, 181-216.

(29)Gross, J.; Sadowski, G. Perturbed-chain SAFT: An equation of state based on a perturbation theory for chain molecules. Industrial \& engineering chemistry research $\mathbf{2 0 0 1}$, $40,1244-1260$.

(30)Gross, J.; Sadowski, G. Application of the perturbed-chain SAFT equation of state to associating systems. Industrial \& engineering chemistry research 2002, 41, 5510-5515.

(31)Li, J.; Polka, H.-M.; Gmehling, J. A gE model for single and mixed solvent electrolyte systems: 1. Model and results for strong electrolytes. Fluid Phase Equilibria 1994, 94, 89114. 
(32)Thomsen, K.; Rasmussen, P. Modeling of vapor-liquid-solid equilibrium in gasaqueous electrolyte systems. Chemical Engineering Science 1999, 54, 1787-1802.

(33)Renon, H.; Prausnitz, J. M. Local compositions in thermodynamic excess functions for liquid mixtures. AIChE journal 1968, 14, 135-144.

(34)Pitzer, K. The Nature of the Chemical Bond and the Structure of Molecules and Crystals: An Introduction to Modern Structural Chemistry. Journal of the American Chemical Society 1960, 82, 4121-4121.

(35)Chen, C. C.; Britt, H. I.; Boston, J.; Evans, L. Local composition model for excess Gibbs energy of electrolyte systems. Part I: Single solvent, single completely dissociated electrolyte systems. AIChE Journal 1982, 28, 588-596.

(36)Song, Y.; Chen, C.-C. Symmetric electrolyte nonrandom two-liquid activity coefficient model. Industrial \& Engineering Chemistry Research 2009, 48, 7788-7797.

(37)Søreide, I.; Whitson, C. H. Peng-Robinson predictions for hydrocarbons, CO2, N2, and $\mathrm{H} 2 \mathrm{~S}$ with pure water and NaCI brine. Fluid Phase Equilibria 1992, 77, 217-240.

(38)Harvey, A. H.; Prausnitz, J. M. Thermodynamics of high-pressure aqueous systems containing gases and salts. AIChE Journal 1989, 35, 635-644.

(39)Aasberg-Petersen, K.; Stenby, E.; Fredenslund, A. Prediction of high-pressure gas solubilities in aqueous mixtures of electrolytes. Industrial \& engineering chemistry research 1991, 30, 2180-2185.

(40)Zuo, Y.-X.; Guo, T.-M. Extension of the Patel—Teja equation of state to the prediction of the solubility of natural gas in formation water. Chemical Engineering Science 1991, 
$46,3251-3258$.

(41)Haghighi, H.; Chapoy, A.; Tohidi, B. Methane and water phase equilibria in the presence of single and mixed electrolyte solutions using the cubic-plus-association equation of state. Oil \& Gas Science and Technology-Revue de l'IFP 2009, 64, 141-154.

(42)Tan, S. P.; Yao, Y.; Piri, M. Modeling the solubility of SO2+ CO2 mixtures in brine at elevated pressures and temperatures. Industrial \& Engineering Chemistry Research 2013, $52,10864-10872$.

(43)Courtial, X.; Ferrando, N.; De Hemptinne, J.-C.; Mougin, P. Electrolyte CPA equation of state for very high temperature and pressure reservoir and basin applications. Geochimica et Cosmochimica Acta 2014, 142, 1-14.

(44)Sun, R.; Dubessy, J. Prediction of vapor-liquid equilibrium and PVTx properties of geological fluid system with SAFT-LJ EOS including multi-polar contribution. Part I: Application to H2O-CO2 system. Geochimica et Cosmochimica Acta 2010, 74, 1982-1998. (45)Sun, R.; Dubessy, J. Prediction of vapor-liquid equilibrium and PVTx properties of geological fluid system with SAFT-LJ EOS including multi-polar contribution. Part II: Application to $\mathrm{H} 2 \mathrm{O}-\mathrm{NaCl}$ and $\mathrm{CO} 2-\mathrm{H} 2 \mathrm{O}-\mathrm{NaCl}$ System. Geochimica et Cosmochimica Acta 2012, 88, 130-145.

(46)Rozmus, J.; de Hemptinne, J.-C.; Galindo, A.; Dufal, S.; Mougin, P. Modeling of strong electrolytes with ePPC-SAFT up to high temperatures. Industrial \& Engineering Chemistry Research 2013, 52, 9979-9994.

(47)Schreckenberg, J. M.; Dufal, S.; Haslam, A. J.; Adjiman, C. S.; Jackson, G.; Galindo, 
A. Modelling of the thermodynamic and solvation properties of electrolyte solutions with the statistical associating fluid theory for potentials of variable range. Molecular Physics 2014, 112, 2339-2364.

(48)Ji, X.; Tan, S. P.; Adidharma, H.; Radosz, M. SAFT1-RPM approximation extended to phase equilibria and densities of $\mathrm{CO} 2-\mathrm{H} 2 \mathrm{O}$ and $\mathrm{CO} 2-\mathrm{H} 2 \mathrm{O}-\mathrm{NaCl}$ systems. Industrial \& engineering chemistry research 2005, 44, 8419-8427.

(49)Maribo-Mogensen, B.; Thomsen, K.; Kontogeorgis, G. M. An electrolyte CPA equation of state for mixed solvent electrolytes. AIChE Journal 2015, 61, 2933-2950.

(50)Kontogeorgis, G. M.; Voutsas, E. C.; Yakoumis, I. V.; Tassios, D. P. An equation of state for associating fluids. Industrial \& engineering chemistry research 1996, 35, 43104318.

(51)Debye, P.; Huckel, E. Phys, Z., 24, 185 (1923); P. Debye. Phys. Z 1924, 25, 93.

(52)Born, M. Volumen und hydratationswärme der ionen. Zeitschrift für Physik A Hadrons and Nuclei 1920, 1, 45-48.

(53)Breil, M. P.; Kontogeorgis, G. M.; Behrens, P. K.; Michelsen, M. L. Modeling of the thermodynamics of the acetic acid- water mixture using the cubic-plus-association equation of state. Industrial \& Engineering Chemistry Research 2011, 50, 5795-5805.

(54)Michelsen, M. L.; Mollerup, J. Thermodynamics models; fundamendals and computational aspects. 1996.

(55)Wertheim, M. Fluids with highly directional attractive forces. I. Statistical thermodynamics. Journal of statistical physics 1984, 35, 19-34. 
(56) Wertheim, M. Fluids with highly directional attractive forces. II. Thermodynamic perturbation theory and integral equations. Journal of statistical physics 1984, 35, 35-47. (57)Chapman, W. G.; Gubbins, K. E.; Jackson, G.; Radosz, M. New reference equation of state for associating liquids. Industrial \& Engineering Chemistry Research 1990, 29, 17091721.

(58)Michelsen, M. L.; Hendriks, E. M. Physical properties from association models. Fluid phase equilibria 2001, 180, 165-174.

(59)Myers, J. A.; Sandler, S. I.; Wood, R. H. An equation of state for electrolyte solutions covering wide ranges of temperature, pressure, and composition. Industrial \& engineering chemistry research 2002, 41, 3282-3297.

(60)Ben-Naim, A. Thermodynamics of aqueous solutions of noble gases. I. The Journal of Physical Chemistry 1965, 69, 3240-3245.

(61)Maribo-Mogensen, B.; Kontogeorgis, G. M.; Thomsen, K. Modeling of dielectric properties of aqueous salt solutions with an equation of state. The Journal of Physical Chemistry B 2013, 117, 10523-10533.

(62)Yan, W.; Huang, S.; Stenby, E. H. Measurement and modeling of CO2 solubility in $\mathrm{NaCl}$ brine and $\mathrm{CO} 2-$ saturated $\mathrm{NaCl}$ brine density. International Journal of Greenhouse Gas Control 2011, 5, 1460-1477.

(63)Drummond, S. Boiling and Mixing of Hydrothermal Fluids: Chemical Effects on Mineral Precipitation. 1982.

(64)Takenouchi, S.; Kennedy, G. C. The solubility of carbon dioxide in NaCl solutions at 
high temperatures and pressures. American journal of science 1965, 263, 445-454.

(65)Koschel, D.; Coxam, J.-Y.; Rodier, L.; Majer, V. Enthalpy and solubility data of CO2 in water and $\mathrm{NaCl}(\mathrm{aq})$ at conditions of interest for geological sequestration. Fluid phase equilibria 2006, 247, 107-120.

(66)Blanco C, L. H.; Smith, N. O. The high pressure solubility of methane in aqueous calcium chloride and aqueous tetraethylammonium bromide. Partial molar properties of dissolved methane and nitrogen in relation to water structure. The Journal of Physical Chemistry 1978, 82, 186-191.

(67)Blount, C. W.; Price, L. C.; Wenger, L. M.; Tarullo, M. Methane solubility in aqueous $\mathrm{NaCl}$ solutions at elevated temperatures and pressures. Proc. 4th US 1979, 1225-1262.

(68)Price, L.; Blount, C.; Gowan, D.; Wenger, L.; Bebout, D.; Bachman, A. Methane solubility in brines with application to the geopressured resource1981.

(69)Duffy, J. R.; Smith, N. O.; Nagy, B. Solubility of natural gases in aqueous salt solutions-I: Liquidus surfaces in the system $\mathrm{CH} 4-\mathrm{H} 2 \mathrm{O}-\mathrm{NaCl} 2-\mathrm{CaCl} 2$ at room temperatures and at pressures below 1000 psia. Geochimica et Cosmochimica Acta 1961, $24,23-31$.

(70)Michels, A.; Gerver, J.; Bijl, A. The influence of pressure on the solubility of gases. Physica 1936, 3, 797-808.

(71)Barta, L.; Bradley, D. J. Extension of the specific interaction model to include gas solubilities in high temperature brines. Geochimica et cosmochimica Acta 1985, 49, 195203. 
(72)Duan, Z.; Mao, S. A thermodynamic model for calculating methane solubility, density and gas phase composition of methane-bearing aqueous fluids from 273 to $523 \mathrm{~K}$ and from 1 to 2000 bar. Geochimica et Cosmochimica Acta 2006, 70, 3369-3386.

(73)Takenouchi, S.; Kennedy, G. C. The binary system H 2 O-CO 2 at high temperatures and pressures. American Journal of Science 1964, 262, 1055-1074.

(74)Tödheide, K.; Franck, E. Das Zweiphasengebiet und die kritische Kurve im System Kohlendioxid-Wasser bis zu Drucken von 3500 bar. Zeitschrift für Physikalische Chemie $1963,37,387-401$.

(75)Sun, L.; Liang, X.; Von Solms, N.; Kontogeorgis, G. M. Modeling Tetra-n-butyl ammonium halides aqueous solutions with the electrolyte cubic plus association equation of state. Fluid Phase Equilibria 2019, 486, 37-47.

(76)Liang, X. Numerical aspects of phase equilibrium calculations with the cubic and association models. Industrial \& Engineering Chemistry Research 2018, 57, 14273-14285. (77) Silberberg, M. S.: Principles of general chemistry; McGraw-Hill Higher Education New York, 2007.

(78)Reid, R. C.; Prausnitz, J. M.; Poling, B. E. The properties of gases and liquids. 1987. (79) Yan, W.; Kontogeorgis, G. M.; Stenby, E. H. Application of the CPA equation of state to reservoir fluids in presence of water and polar chemicals. Fluid Phase Equilibria 2009, $276,75-85$.

(80)Tsivintzelis, I.; Kontogeorgis, G. M.; Michelsen, M. L.; Stenby, E. H. Modeling phase equilibria for acid gas mixtures using the CPA equation of state. Part II: Binary mixtures 
with CO2. Fluid Phase Equilibria 2011, 306, 38-56.

(81)King, M.; Mubarak, A.; Kim, J.; Bott, T. The mutual solubilities of water with supercritical and liquid carbon dioxides. The Journal of Supercritical Fluids 1992, 5, 296302.

(82)Wiebe, R.; Gaddy, V. The solubility in water of carbon dioxide at 50, 75 and 100, at pressures to 700 atmospheres. Journal of the American Chemical Society 1939, 61, 315318.

(83)Valtz, A.; Chapoy, A.; Coquelet, C.; Paricaud, P.; Richon, D. Vapour-liquid equilibria in the carbon dioxide-water system, measurement and modelling from 278.2 to $318.2 \mathrm{~K}$. Fluid phase equilibria 2004, 226, 333-344.

(84)Bamberger, A.; Sieder, G.; Maurer, G. High-pressure (vapor+ liquid) equilibrium in binary mixtures of (carbon dioxide+ water or acetic acid) at temperatures from 313 to 353

K. The Journal of Supercritical Fluids 2000, 17, 97-110.

(85)Wiebe, R.; Gaddy, V. The solubility of carbon dioxide in water at various temperatures from 12 to 40 and at pressures to 500 atmospheres. Critical phenomena. Journal of the American Chemical Society 1940, 62, 815-817.

(86)Müller, G.; Bender, E.; Maurer, G. Das Dampf-Flüssigkeitsgleichgewicht des ternären Systems Ammoniak-Kohlendioxid-Wasser bei hohen Wassergehalten im Bereich zwischen 373 und 473 Kelvin. Berichte der Bunsengesellschaft für physikalische Chemie 1988, $92,148-160$.

(87)Lin, W.; Delahaye, A.; Fournaison, L. Phase equilibrium and dissociation enthalpy for 
semi-clathrate hydrate of CO2+ TBAB. Fluid Phase Equilibria 2008, 264, 220-227.

(88)Lekvam, K.; Bishnoi, P. R. Dissolution of methane in water at low temperatures and intermediate pressures. Fluid Phase Equilibria 1997, 131, 297-309.

(89)Culberson, O.; McKetta Jr, J. Phase equilibria in hydrocarbon-water systems III-the solubility of methane in water at pressures to 10,000 psia. Journal of Petroleum Technology

1951, 3, 223-226.

(90)Dodson, C.; Standing, M. In Tilte1944; American Petroleum Institute.

(91)Claussen, W.; Polglase, M. Solubilities and structures in aqueous aliphatic hydrocarbon solutions. Journal of the American Chemical Society 1952, 74, 4817-4819.

(92)Culberson, O.; Horn, A. B.; McKetta Jr, J. Phase equilibria in hydrocarbon-water systems. Journal of Petroleum Technology 1950, 2, 1-6.

(93)Morrison, T.; Billett, F. 730. The salting-out of non-electrolytes. Part II. The effect of variation in non-electrolyte. Journal of the Chemical Society (Resumed) 1952, 3819-3822. (94)Yang, S.; Cho, S.; Lee, H.; Lee, C. Measurement and prediction of phase equilibria for water+ methane in hydrate forming conditions. Fluid Phase Equilibria 2001, 185, 53-63. (95)Lindenbaum, S.; Boyd, G. Osmotic and activity coefficients for the symmetrical tetraalkyl ammonium halides in aqueous solution at 25. The Journal of Physical Chemistry 1964, 68, 911-917.

(96)Robinson, R. A.; Stokes, R. H. Tables of osmotic and activity coefficients of electrolytes in aqueous solution at 25 C. Transactions of the Faraday Society 1949, 45, $612-624$. 
(97)Pabalan, R. T.; Pitzer, K. S. Apparent molar heat capacity and other thermodynamic properties of aqueous potassium chloride solutions to high temperatures and pressures. Journal of Chemical and Engineering Data 1988, 33, 354-362.

(98)Rard, J. A.; Habenschuss, A.; Spedding, F. H. A review of the osmotic coefficients of aqueous calcium chloride at 25. degree. C. Journal of Chemical and Engineering Data 1977, 22, 180-186.

(99)Rard, J. A.; Miller, D. G. Isopiestic determination of the osmotic and activity coefficients of aqueous magnesium chloride solutions at 25. degree. C. Journal of Chemical and Engineering Data 1981, 26, 38-43.

(100) El Guendouzi, M.; Marouani, M. Water activities and osmotic and activity coefficients of aqueous solutions of nitrates at $25 \mathrm{C}$ by the hygrometric method. Journal of solution chemistry 2003, 32, 535-546.

(101) Liu, Y.; Hou, M.; Yang, G.; Han, B. Solubility of CO2 in aqueous solutions of $\mathrm{NaCl}, \mathrm{KCl}, \mathrm{CaCl} 2$ and their mixed salts at different temperatures and pressures. The Journal of supercritical fluids 2011, 56, 125-129.

(102) Bando, S.; Takemura, F.; Nishio, M.; Hihara, E.; Akai, M. Solubility of CO2 in aqueous solutions of $\mathrm{NaCl}$ at (30 to 60$) \mathrm{C}$ and (10 to 20) $\mathrm{MPa}$. Journal of Chemical \& Engineering Data 2003, 48, 576-579.

(103) Markham, A. E.; Kobe, K. A. The solubility of carbon dioxide and nitrous oxide in aqueous salt solutions. Journal of the American Chemical Society 1941, 63, 449-454.

(104) Messabeb, H.; Contamine, F. o.; Cézac, P.; Serin, J. P.; Gaucher, E. C. 
Experimental Measurement of $\mathrm{CO} 2$ Solubility in Aqueous $\mathrm{NaCl}$ Solution at Temperature from 323.15 to $423.15 \mathrm{~K}$ and Pressure of up to $20 \mathrm{MPa}$. Journal of Chemical \& Engineering Data 2016, 61, 3573-3584.

(105) Guo, H.; Huang, Y.; Chen, Y.; Zhou, Q. Quantitative Raman Spectroscopic Measurements of $\mathrm{CO} 2$ Solubility in $\mathrm{NaCl}$ Solution from $(273.15$ to 473.15$) \mathrm{K}$ at $\mathrm{p}=(10.0$, 20.0, 30.0, and 40.0) MPa. Journal of Chemical \& Engineering Data 2015, 61, 466-474.

(106) O'Sullivan, T. D.; Smith, N. O. Solubility and partial molar volume of nitrogen and methane in water and in aqueous sodium chloride from 50 to 125 . deg. and 100 to 600 atm. The Journal of Physical Chemistry 1970, 74, 1460-1466.

(107) Stoessell, R. K.; Byrne, P. A. Salting-out of methane in single-salt solutions at 25 C and below 800 psia. Geochimica et Cosmochimica Acta 1982, 46, 1327-1332.

(108) Zhao, H.; Dilmore, R. M.; Lvov, S. N. Experimental studies and modeling of CO2 solubility in high temperature aqueous $\mathrm{CaCl} 2, \mathrm{MgCl} 2, \mathrm{Na} 2 \mathrm{SO} 4$, and $\mathrm{KCl}$ solutions. AIChE Journal 2015, 61, 2286-2297.

(109) Kiepe, J.; Horstmann, S.; Fischer, K.; Gmehling, J. Experimental determination and prediction of gas solubility data for methane+ water solutions containing different monovalent electrolytes. Industrial \& engineering chemistry research 2003, 42, 5392-5398. (110) Tong, D.; Trusler, J. M.; Vega-Maza, D. Solubility of CO2 in aqueous solutions of $\mathrm{CaCl} 2$ or $\mathrm{MgCl} 2$ and in a synthetic formation brine at temperatures up to $423 \mathrm{~K}$ and pressures up to $40 \mathrm{MPa}$. Journal of Chemical \& Engineering Data 2013, 58, 2116-2124.

(111) Messabeb, H.; Contamine, F. o.; Cézac, P.; Serin, J. P.; Pouget, C. m.; Gaucher, 50 
E. C. Experimental Measurement of $\mathrm{CO} 2$ Solubility in Aqueous $\mathrm{CaCl} 2$ Solution at Temperature from 323.15 to $423.15 \mathrm{~K}$ and Pressure up to $20 \mathrm{MPa}$ Using the Conductometric Titration. Journal of Chemical \& Engineering Data 2017, 62, 4228-4234. (112) Prutton, C.; Savage, R. The solubility of carbon dioxide in calcium chloride-water solutions at 75, 100, 120 and high pressures1. Journal of the American Chemical Society 1945, 67, 1550-1554.

(113) Hyde, A. M.; Zultanski, S. L.; Waldman, J. H.; Zhong, Y.-L.; Shevlin, M.; Peng, F. General principles and strategies for salting-out informed by the Hofmeister series. Organic Process Research \& Development 2017, 21, 1355-1370.

(114) Carvalho, P. J.; Pereira, L. M.; Gonçalves, N. P.; Queimada, A. J.; Coutinho, J. A. Carbon dioxide solubility in aqueous solutions of $\mathrm{NaCl}$ : Measurements and modeling with electrolyte equations of state. Fluid Phase Equilibria 2015, 388, 100-106.

(115) Dinane, A.; El Guendouzi, M.; Mounir, A. Hygrometric determination of water activities, osmotic and activity coefficients of $(\mathrm{NaCl}+\mathrm{KCl})(\mathrm{aq})$ at $\mathrm{T}=298.15 \mathrm{~K}$. The Journal of Chemical Thermodynamics 2002, 34, 423-441.

(116) Saad, D.; Padova, J.; Marcus, Y. Thermodynamics of mixed electrolyte solutions. VI. An isopiestic study of a pseudo-ternary system: $\mathrm{NaCl}-\mathrm{KCl}-\mathrm{MgCl} 2-\mathrm{H} 2 \mathrm{O}$ at $25^{\circ} \mathrm{C}$. Journal of Solution Chemistry 1975, 4, 983-993.

(117) Wood, J. R. Thermodynamics of brine-salt equilibria- - I. The systems NaCl-KCl$\mathrm{MgCl} 2-\mathrm{CaCl} 2-\mathrm{H} 2 \mathrm{O}$ and $\mathrm{NaCl}-\mathrm{MgSO} 4-\mathrm{H} 2 \mathrm{O}$ at $25 \mathrm{C}$. Geochimica et Cosmochimica Acta 1975, 39, 1147-1163. 
(118) Robinson, R.; Covington, A. The thermodynamics of the ternary system: Waterpotassium chloride-calcium chloride at 25 C. J. Res. Natl. Bur. Stand. A 1968, 72, 239.

(119) Christov, C. Isopiestic determination of the osmotic coefficients of an aqueous $\mathrm{MgCl} 2+\mathrm{CaCl} 2$ mixed solution at $(25 \text { and } 50)^{\circ} \mathrm{C}$. Chemical equilibrium model of solution behavior and solubility in the $\mathrm{MgCl} 2+\mathrm{H} 2 \mathrm{O}$ and $\mathrm{MgCl} 2+\mathrm{CaCl} 2+\mathrm{H} 2 \mathrm{O}$ systems to high concentration at $(25 \text { and } 50)^{\circ}$ C. Journal of Chemical \& Engineering Data 2008, 54, 627635.

(120) Byrne, P. A.; Stoessell, R. K. Methane solubilities in multisalt solutions. Geochimica et Cosmochimica Acta 1982, 46, 2395-2397.

(121) Jacob, R.; Saylor, B. Z. CO2 solubility in multi-component brines containing $\mathrm{NaCl}, \mathrm{KCl}, \mathrm{CaCl} 2$ and $\mathrm{MgCl} 2$ at $297 \mathrm{~K}$ and 1-14 MPa. Chemical Geology 2016, 424, 8695.

(122) Samoilov, O. Y. A new approach to the study of hydration of ions in aqueous solutions. Discussions of the Faraday Society 1957, 24, 141-146.

(123) Collins, K. D. Charge density-dependent strength of hydration and biological structure. Biophysical journal 1997, 72, 65-76.

(124) Görgényi, M.; Dewulf, J.; Van Langenhove, H.; Héberger, K. Aqueous saltingout effect of inorganic cations and anions on non-electrolytes. Chemosphere 2006, 65, 802810.

(125) Held, C.; Reschke, T.; Muller, R.; Kunz, W.; Sadowski, G. Measuring and modeling aqueous electrolyte/amino-acid solutions with ePC-SAFT. The Journal of 
Chemical Thermodynamics 2014, 68, 1-12.

(126) Uyan, M.; Sieder, G.; Ingram, T.; Held, C. Predicting CO2 solubility in aqueous N-methyldiethanolamine solutions with ePC-SAFT. Fluid Phase Equilibria 2015, 393, 91100.

(127) Wangler, A.; Sieder, G.; Ingram, T.; Heilig, M.; Held, C. Prediction of CO 2 and H 2 S solubility and enthalpy of absorption in reacting N-methyldiethanolamine /water systems with ePC-SAFT. Fluid Phase Equilibria 2017, 461, 15-27. 
For Table of Contents Only

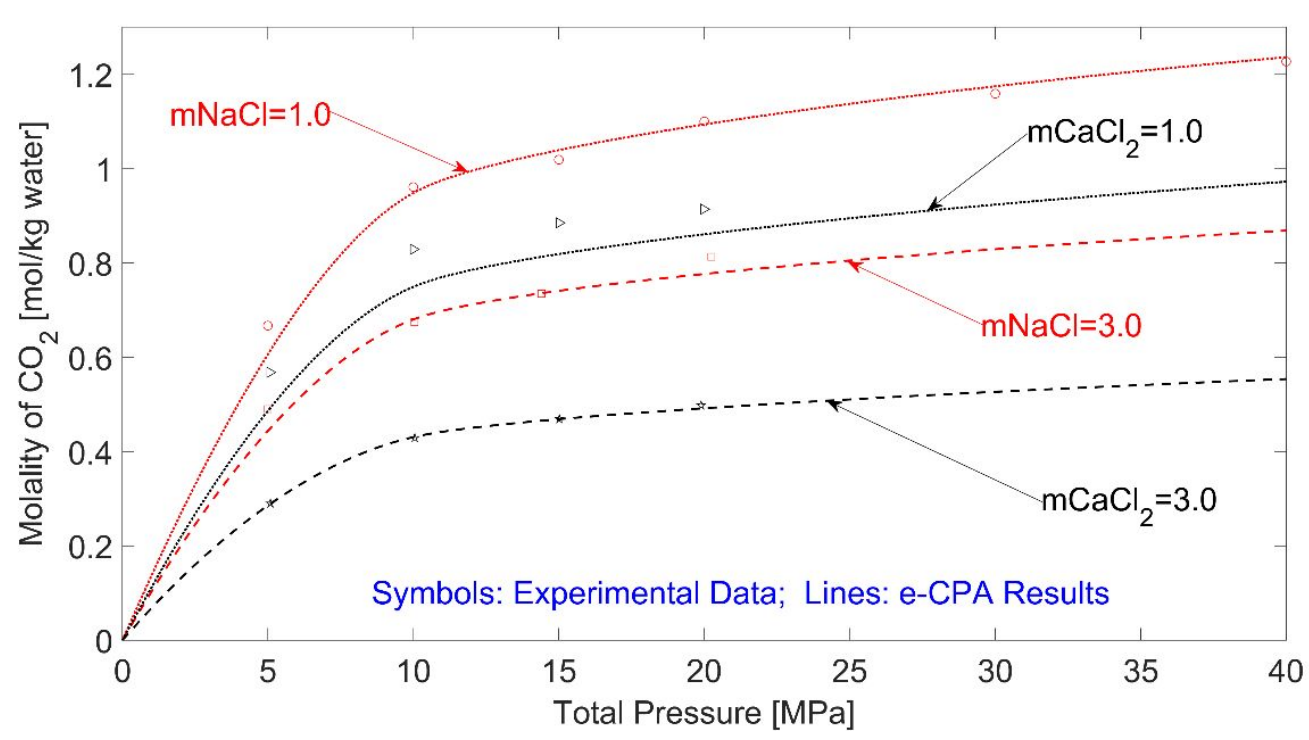




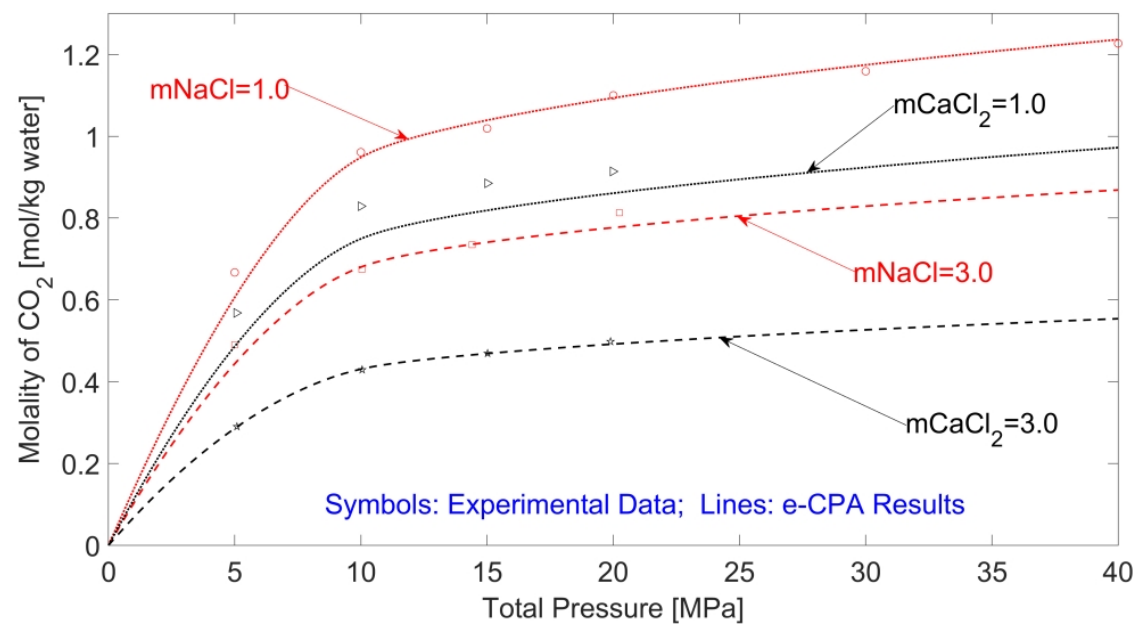

$362 \times 183 \mathrm{~mm}(300 \times 300$ DPI $)$ 